\title{
A liposome-based cancer vaccine for a rapid and high-titre anti-ErbB-2 antibody response
}

\author{
Jamie Wallis $^{\mathrm{a}}$, Prateek Katti ${ }^{\mathrm{a}}$, Alexander M. Martin ${ }^{\mathrm{a}}$, Tom Hills ${ }^{\mathrm{b}}$, Leonard \\ W. Seymour ${ }^{\mathrm{b}}$, Daniel P. Shenton ${ }^{\mathrm{c}}$, Robert C. Carlisle ${ }^{\mathrm{a}, *}$ \\ ${ }^{a}$ Institute of Biomedical Engineering, University of Oxford, UK \\ ${ }^{b}$ Department of Oncology, University of Oxford, UK \\ ${ }^{c}$ Defence Science and Technology Laboratory, Porton Down, UK
}

\begin{abstract}
Vaccines are arguably the most important medical technology developed to date. However, effective treatment of diseases such as breast cancer have so far evaded standard vaccination strategies. One popular target for cancer treatment is the cell surface membrane protein, ErbB-2, also known as Her-2 or neu. It is localised to the cell surface and has raised expression in $15-30 \%$ of all breast cancers, as well as in ovarian, colon and lung cancer. Here, a liposomal system comprised of spatially separated ErbB-2 peptide, to activate B cells, and ovalbumin peptide $\mathrm{OVA}_{323-339}$, to provide non-cognate $\mathrm{T}$ cell support, was used to generate antibodies against the epitope of the ErbB-2 protein targeted by Pertuzumab, a monoclonal antibody licensed for the treatment of ErbB2 expressing cancers. After just 7 days a raised (7.3-fold, pi0.01), isotypeswitched, humoral immune response specific for the ErbB-2 peptide was achieved in mice with pre-existing immunity of OVA which were exposed to liposomes with external ErbB-2 and internal $\mathrm{OVA}_{323-339}$. The absence of pre-existing OVA immunity in the mice or $\mathrm{OVA}_{323-339}$ peptide in the liposomes removed the effect. The effect of this anti-ErbB-2 antibody response was characterised against an ErbB-2 overexpressing tumour cell line both in vitro and in vivo. Notably, antibody responses were demonstrated to induce cell death in vitro,
\end{abstract}

\footnotetext{
* Robert Carlisle

Email address: robert.carlisle@eng.ox.ac.uk (Robert C. Carlisle)
}

Preprint submitted to European Journal of Pharmaceutical Sciences

June 2, 2020 
resulting in $96 \%$ reduction in viable cells. This study, therefore, demonstrates the feasibility of this approach to generate a rapid, high-titre, isotype-switched, antibody response that specifically targets ErbB-2 overexpression on tumour cells and is capable of inducing cell death in vitro in the absence of complement or immune cells.

Keywords: Cancer, Liposome, Vaccine, Vaccination

\section{Introduction}

There have been dramatic reductions in the mortality and morbidity resulting from infectious disease since Edward Jenner first developed his smallpox vaccine. The World Health Organization (WHO) estimates that vaccinations

5 for diphtheria, tetanus, whooping cough, and measles currently prevent $2-3$ million deaths per year [1. Although vaccines have been undeniably successful, improvements in vector production and ease of use would still be of great benefit. In particular, effective vaccines for cancer have for the most part evaded standard vaccination technologies. Promising new approaches are increasingly exploiting an improved knowledge of the immune system to design the next generation of vaccines $[2]$.

The development of targeted cancer therapies which can have a systemic effect is a priority. An important first step in this process is the identification of cancer cell-associated targets that play a key role in their growth and survival. One popular target for cancer treatment is the cell surface protein, ErbB-2, also known as Her-2 or neu. In particular, overexpression of ErbB-2 occurs in $15-30 \%$ of all breast cancers, as well as in other cancers, including ovarian, colon and lung [3]. Some cancer patients have shown the ability to mount weak immune responses against ErbB-2, indicating that it is possible to overcome self-tolerance and initiate an immune response against ErbB-2 overexpressing cancerous cells 4, 5. This makes ErbB-2 an appealing target for cancer immunotherapy. The FDA-approved, humanised monoclonal antibodies, Trastuzumab and Pertuzumab, are currently used for ErbB-2 overexpressing 
breast cancers. Typically for Trastuzumab patients will receive a dose every three weeks over the course of one year. The efficacy of these biologic agents and their relatively favourable toxicity profile compared to conventional chemotherapeutics means they are viewed as an important part of cancer therapy. However, whilst antibodies represent a growing class of therapeutics despite their great expense, they are, as of yet, rarely completely curative, meaning there is much contention regarding their impact on healthcare economics [6]. Therefore, there is interest in developing vaccines that are both prophylactic and therapeutic that could induce a sustainable ErbB-2 targeted immune response and have a lower comparative cost.

ErbB-2 targeted vaccines often aim at eliciting a cytotoxic $\mathrm{T}$ cell response 35 [7, 8]. However, due to the clinical success of monoclonal anti-ErbB-2 antibody therapies (Trastuzumab and Pertuzumab), it is of interest to generate a humoral response from an ErbB-2 targeted vaccine that is more cost effective than these therapies. Indeed, there are several clinical trials underway that aim at eliciting an anti-ErbB-2 humoral response 9, 10. Generation of an ErbB-2 humoral response to a peptide-based vaccine is harder to achieve than a cellular response due to the requirement that the peptide needs to be a good model of the native structure of the cancer antigen. In contrast, in order to generate a cellular response, peptide-vaccines do not need to be conformationally similar due to the pre-processing of the peptides prior to MHC presentation. Peptide-based vaccines designed to elicit $\mathrm{B}$ cell responses must also achieve $\mathrm{T}$ cell stimulation in order to receive the necessary $\mathrm{T}$ helper cell signalling, this is most commonly done by conjugation of the peptide to a large helper molecule, such as tetanus toxoid or keyhole limpet hemocyanin [11, 12].

Liposomes have mainly been used in vaccinology as either a delivery vehicle ${ }_{50}$ or as an adjuvant [13, 14]. A key advantage of liposomes is their plasticity and versatility; the choice of lipids and their formulation method allows control over their charge, size and location of antigen incorporation [15. Some cationic liposomes, unlike anionic liposomes, are able to bypass the endosomal-lysosomal route of degradation in cells [16]. Antigens can be encapsulated within, con- 
jugated to the surface of, or embedded within the lipid bilayer of liposomes [17, 18. The location of an antigen in or on liposomes influences the type of immune response generated towards the vaccine. T cell responses are induced by both encapsulated and surface-conjugated antigens, while B cell responses are exclusively induced by surface-conjugated antigens [13].

We have previously reported the development of a vaccine approach for malaria which makes use of peptides and liposomes [18. Like traditional fusion peptide methods, this vaccine system works by boosting the immune response to the target, 'weak', antigen by taking advantage of pre-existing immunity to a second, 'strong', antigen. However, our approach differs from traditional peptide conjugate vaccines as the liposomes utilised are formed by encapsulating the strong antigen within the liposome and presenting the weak antigen exclusively on the liposome surface. Thereby, this strategy spatially segregates the weak and strong antigens, focusing the B cell response exclusively onto the external weak target antigen. This prevents the humoral immune response from being focused on the strong, helper antigents [19. The proposed mechanism of action is shown in the schematic in supplementary figure S1. B cells with receptors specific for the liposomal surface antigen can, upon contact with the liposomes, phagocytose the vaccine particles. Endosomal conditions lead to degradation of the liposomes and the generation of peptide fragments from both the weak 75 and strong antigens. These peptides are then presented on B cell MHC class II molecules on the cell surface for CD4+ helper $\mathrm{T}$ cell recognition. Helper CD4+ T cells can recognise the same epitope as the B cell (cognate) or another protein simultaneously taken up by the B cell (non-cognate). Pre-existing non-cognate $\mathrm{CD} 4+$ helper $\mathrm{T}$ cells that recognise the strong antigen provide costimulatory signals to the B cell, resulting in confirmation of antibody production [20]. These signals in turn lead to B cell proliferation, differentiation, antibody production, somatic hypermutation and isotype switching. As the specificity of this antibody response was initiated at the point of $\mathrm{B}$ cell receptor mediated recognition of the external weak antigen on the liposomes, the antibodies produced will exclusively target the weak antigen. In our previous studies we used 
malaria circumsporozoite (CSP) as the weak antigen and an ovalbumin (OVA) $\mathrm{T}$ cell epitope as the encapsulated strong antigen. We showed that in mice with pre-existing anti-OVA CD4+ $\mathrm{T}$ cell immunity the vaccine evokes a rapid, high titre, isotype switched CSP-specific antibody response. This was shown to be consistent with the involvement of the anti-OVA $\mathrm{T}$ helper cells in confirming activation of anti-CSP B cells [18. Some previous studies have taken advantage of strong $\mathrm{T}$ helper epitopes incorporated into liposomal vaccines [21, 22, but our method of spatially segregating the target and helper peptides focuses the immune response specifically onto the weak target antigen. Our method of spatial segregation of target and helper antigens differes importantly from traditional conjugate or virus-like particle based vaccine strategies, which can be limited by dominance of the immune response against the helper molecule [19, 23].

Here we describe the formulation and testing of a synthetic vaccine against tumours overexpressing ErbB-2 by using the liposomal vaccine method described previously [18. The external, weak antigen used is a modified version of the immunogenic ErbB-2 $266-296$ peptide described by Allen et al. currently used in an ongoing phase I clinical trial [24, 9]. The internal, strong antigen used was the model antigen, $\mathrm{OVA}_{323-339}$. After physicochemical characterisation of the liposomes their ability to raise an anti-ErbB-2 antibody response in both $\mathrm{BALB} / \mathrm{c}$ and $\mathrm{FVB} / \mathrm{n}$ mice was studied. $\mathrm{FVB} / \mathrm{n}$ mice provide a useful control as they lack the MHC II haplotype capable of presenting the OVA peptide and so this removes the possibility of OVA driven non-cognate CD4+ T cell help [25, 26].

\section{Material and Methods}

\subsection{Epitopes}

OVA $_{323-339}$ peptide (Innovagen, Sweden) is a T cell epitope with the sequence ISQAVHAAHAEINEAGR. OVA peptide for a control liposomal formulation with external OVA peptide was custom-made with a single cysteine 
thesised by custom peptide synthesis at ThermoScientific, Germany). ErbB266-296 peptide (synthesised by custom peptide synthesis at ThermoScientific, Germany) mimics the Pertuzumab binding region on the native ErbB-2 protein, with the sequence CGPSLLHCPALVTYNTDTFESMHNPEGRYTFtide described by Allen et al. 24 in which the measles virus fusion helper peptide used is replaced with a single cysteine residue for liposome conjugation purposes.

\subsection{Liposomal Formulation}

125

Liposomes were formed by lyophilisation as described by Szoka and Papahadjopoulos [27]. Briefly, lipids were dissolved in a 2:1 chloroform:methanol mix in a freeze-drying vial, to achieve a total lipid concentration of $20-40 \mathrm{mg} / \mathrm{mL}$. Liposomes were prepared to contain 43 mol\% DMPC (1,2 - dimyristoyl - sn glycero - 3 - phosphocholine, Avanti Polar Lipids, USA), 42 mol\% Cholesterol 130 (Sigma Aldrich, UK), 10 mol\% DSPE-PEG2000-maleimide (1,2 - distearoyl - sn - glycero3 - phosphoethanolamine - N - [maleimide(polyethylene glycol) - 2000], Avanti Polar Lipids, USA), and 5 mol\% DMPG (Avanti Polar Lipids, USA).

The chloroform and methanol was then removed using a high vacuum pump overnight, leaving a lipid film on the bottom of the vial. The dried lipids were then re-dissolved in cyclohexane to a concentration of $20-40 \mathrm{mg} / \mathrm{mL}$. The lipidcyclohexane mixture was flash frozen by dipping the vial into liquid nitrogen before being placed into a pre-cooled $\left(-30^{\circ} \mathrm{C}\right)$ freeze dryer (FTS Lyostar I freeze drying system, SP Industries, USA). Primary drying was carried out at $-50^{\circ} \mathrm{C}$ for 12 hours and secondary drying was performed at $20^{\circ} \mathrm{C}$ for 6 hours. Pressure 140 was kept constant at 50 mtorr during both drying phases. Freeze dryer vials were then removed from the freeze dryer and the lipid cakes were hydrated with $1 \mathrm{~mL}$ citrate buffer (20 mM, pH 6.3) containing $1 \mathrm{mg}$ of $\mathrm{OVA}_{323-339}$. The resulting liposome-OVA mixture was then extruded at $50^{\circ} \mathrm{C}$ on a hot plate eleven times through a 400nm Nanosizer MINI (t\&tScientific, USA) followed by 
Liposomes were purified using a PBS-washed Sephadex G-75 filled size exclusion column (Sigma Aldrich, UK) and collected into fractions. Purified liposomes, in PBS, were immediately added to $100 \mu \mathrm{L}$ of ErbB-2 or Oc peptide, also in PBS, at a concentration of $10 \mathrm{mg} / \mathrm{mL}$ and left to react for 24 hours at $4^{\circ} \mathrm{C}$. To remove

\subsection{Zeta Potential}

Surface charge of the liposomes was characterised by zeta potential using the Zetasizer instrument with a $1 \mathrm{~mL}$ dilution of 3:100 in PBS in disposable folded capillary cells (Malvern, UK). Data was analysed using Malvern Zetasizer software v6.32.

\subsection{Enzyme-linked immunosorbant assay (ELISA)}

Antigen was plated onto Nunc Immuno MaxiSorp 96 well plates (Sigma Aldrich, UK). Plates were sealed and incubated overnight at $4^{\circ} \mathrm{C}$. Wells were washed 6 times with $0.05 \%$ Tween-20 in PBS, blocked with 10\% FCS in PBS and incubated at RT for 1 hour. Plates were again washed 6 times before addition of primary antibody or sample diluted, to a specified dilution, in PBS. After 2 hour incubation at RT plates were washed 6 times and secondary antibody conjugated 
to HRP was added in a 1:10000 dilution in PBS. Plates were then incubated for 1 hour at RT before being washed a final 6 times. Ultra-TMB HRP substrate

175 (ThermoFisher, UK: 34029) was added to each sample well. After 30 minutes the reaction was stopped by the addition of $0.5 \mathrm{M}$ sulfuric acid. Absorbance of the plate was then read at $450 \mathrm{~nm}$ using a BMG LABTECH FLUOstar Omega plate reader, data was analysed using Omega software version 3.00 R2.

\subsection{ELISA for peptide concentrations}

ELISAs were used to quantify peptide concentrations in liposome samples as described above with liposome sample as the initial antigen and either antiOVA $_{323-339}$ antibody (Innovagen, Sweden: PA-O323-100) or plasma from pilot studies containing anti-ErbB- $2_{266-296}$ antibodies as the primary antibody. Secondary antibodies used were a HRP conjugated anti-rabbit IgG antibody 185 (Abcam, UK: A0545) for $\mathrm{OVA}_{323-339}$ peptide quantification or a HRP conjugated anti-mouse IgG antibody (Sigma Aldrich, UK: A4416) for ErbB-2 $266-296$ peptide quantification.

ELISAs were also used to confirm purification of liposome samples from nonencapsulated OVA peptide with eluted fractions from a size exclusion column

being used as the initial antigen, anti-OVA $323-339$ antibody (Innovagen, Sweden) as the primary antibody and a HRP conjugated anti-rabbit IgG antibody (Abcam, UK) as the secondary.

\subsection{Phospholipid quantification}

Phospholipid concentration of liposomal samples was measured using a phospholipid assay kit (Sigma Aldrich, UK: MAK122-1KT) according to manufacturers instructions.

\subsection{Protein A purification}

A protein A purification kit (ThermoFisher, UK) was used to confirm encapsulation of OVA peptide. Briefly, protein A spin columns were washed and reconstituted with anti-OVA $323-339$ antibody (Innovagen, Sweden). Unbound 
antibody was removed by washing 3 times with binding buffer before incubation with pre-diluted liposomal samples for 10 minutes with end-over-end mixing. Liposome samples were diluted to contain a calculated OVA concentration of $0.2 \mu \mathrm{g}$. Columns were then spun at $5000 \mathrm{xg}$ and resulting flow-through was collected and assayed for OVA peptide concentration by ELISA. Control samples consisted of either empty liposomes (negative control) or liposomes surface decorated with Oc peptide (positive control).

\subsection{Cell lines}

Human lung carcinoma cells, A549 were purchased from the European Collection of Authenticated Cell Cultures, UK and maintained according to the suppliers' guidelines. TUBO cells were gifted from Dr Natalia Saveyeva at the University of Southampton, UK and were maintained similarly to A549 cells with the exception that TUBO cells were grown in high glucose DMEM media supplemented with $20 \%$ FBS. TUBO cells are mouse mammary gland tumour cells spontaneously generated from a BALB-neuT mouse, which highly overexpress the rat ErbB-2 protein on their cell surface [28]. A549 cells were used to test the cytotoxicity of the liposomes, while TUBO cells were used to test the ability of the generated antibodies to bind to their target on tumour cells and their ability to induce in vitro cell death. TUBO cells were also used in challenge studies. TUBO cell lysate was obtained using ice-cold NP40 lysis buffer made using $150 \mathrm{mM}$ sodium chloride (Sigma Aldrich, UK), 50mM Tris $\mathrm{pH} 8.0$ (Sigma Aldrich, UK) and 1\% Triton X-100 (Sigma Aldrich, UK).

\subsection{In vitro cytotoxicity}

Liposomal cytotoxicity tests were performed on A549 by an MTS assay. On day 1, cells per well were plated out onto a sterile 96 well plate (Sigma Aldrich, UK) at a density of 10,000 cells per well. The plate was then incubated at $37^{\circ} \mathrm{C}$ for 24 hours before the media in the wells was removed and replenished with media mixed with varying liposome concentrations $(0,0.2,1,5,10 \%)$, with $\mathrm{n}=5$ repeats of each concentration. The plates were then incubated for 
and replaced with media containing $20 \%$ MTS (3-(4,5-dimethylthiazol-2-yl)-5(3-carboxymethoxyphenyl)-2-(4-sulfophenyl)-2H-tetrazolium, Promega, USA). The plate was incubated for 15 minutes before reading absorbance at $490 \mathrm{~nm}$.

\subsection{Flow cytometry of TUBO cells}

at RT before being centrifuged as before. All tissue samples were then washed twice with PBS by centrifugation to remove free protein. After the last wash, tumour cells and splenocytes were resuspended in PBS to a concentration of 100 
$\mu \mathrm{g}$ of starting tissue/mL to adjust for approximate number of cells. Samples imentation was performed in accordance with institutional and UK Home Office guidelines. All mice showed consistent weight gain throughout the experiment and there was no evidence of toxicity (piloerection, lack of movement/activity, lack of socialisation, etc.) in any mouse. At the cinclusion of the experiment, 285 were then aliquoted into a round-bottomed 96 well plate, with $200 \mu \mathrm{L}$ of each sample. Plates were then centrifuged at $520 \mathrm{xg}$ for 5 minutes at $4^{\circ} \mathrm{C}$ before removal of the supernatant. Cell pellets were resuspended in a given dilution of Zombie Violet viability stain (Biolegend, USA) in PBS (table S1) and incubated at RT in the dark for 20 minutes. Plates were then centrifuged and cell pellets were resuspended in 1:40 dilution of purified anti-mouse CD16/32 antibody (Biolegend, USA) in FACS Buffer and incubated in the dark at $4^{\circ} \mathrm{C}$ for 15 minutes in order to block cellular Fc receptors. Plates were again centrifuged, and cell pellets were resuspended in a given antibody panel stain (table S1) diluted in FACS buffer. Plates were incubated for 30 minutes in the dark at $4^{\circ} \mathrm{C}$, before being centrifuged, and washed once in FACS Buffer. Samples were then loaded onto and run on a Becton Dickson FACSCanto II until 500,000 nondebris events were collected. Pooled single-cell suspensions of individual tissue types were used for single-marker staining and full-minus-one (FMO) staining to aid in gating strategies. Data was then analysed using the software FlowJo version 10 (FlowJo LLC, USA).

\subsection{Mice}

Female BALB/c and FVB/n mice were purchased from Charles Rivers at 4 - 6 weeks old, housed in specific-pathogen-free conditions at the University of Oxford animal facility and used between 5 and 18 weeks of age. Animal weights were recorded twice a week from the start of treatment until cull. Animal experpost-cull, major mouse organs including the heart (important with respect to potential cardiotoxicity) showed normal appearance and weight. 


\subsection{Vaccination}

All injections were performed subcutaneously under anaesthetic. Mice first received a dose of either PBS or $\mathrm{OVA}_{323-339}$ peptide mixed with adjuvant in a 1:1 dilution. Adjuvant used was either TitreMax Gold (TMG) (Sigma Aldrich, UK) or Addavax (Invivogen, France) as specified in figure captions. Mice receiving the $\mathrm{OVA}_{323-339}$ dose were administered a total of $10 \mu \mathrm{g}$ of peptide. An identical booster OVA or PBS dose was given 2 weeks later. After a further 2 weeks, mice were vaccinated with: PBS; free ErbB-2 $266-296$ peptide, denoted 'E'; ErbB-2 266-296 presenting, empty liposomes, denoted 'E()'; or OVA $323-339$ encapsulating, ErbB-2 266-296 presenting liposomes, denoted 'E(O)'.

\subsection{Plasma collection}

Weekly blood samples were collected from the tail vein of mice after dosing with liposomal vaccines. Blood samples were immediately diluted 1:10 in PBS before being centrifuged at $1000 \mathrm{xg}$ for 5 minutes. Supernatants were collected and frozen at $-20^{\circ} \mathrm{C}$ until analysis.

\subsection{ELISA for anti-ErbB-2 humoral responses}

ELISAs were performed to quantify the anti-ErbB-2 total IgG titre in plasma samples as described above, using ErbB-2 $266-296$ as the initial antigen at a concentration of $10 \mu \mathrm{g} / \mathrm{mL}$. Plasma used from mice was at varying dilutions as the primary antibody and a HRP conjugated anti-mouse IgG antibody as the secondary (Sigma Aldrich, UK: A4416). The titre of plasma was defined to be the last dilution tested that gave an absorbance reading above 0.05 after subtraction of the average absorbance and 2 standard deviations of 16 blank wells treated with PBS instead of plasma.

ELISAs were also used to quantify anti-ErbB-2 IgM, IgG1, IgG2a, IgG2b, IgG3 concentrations in mouse blood using ErbB-2 $266-296$ as the initial antigen at a concentration of $10 \mu \mathrm{g} / \mathrm{mL}$. Plasma used from mice was at varying dilutions as the primary antibody and a HRP conjugated anti-mouse IgM, IgG1, IgG2a, 315 IgG2b or IgG3 antibody as the secondary (Abcam, UK: ab97240, ab97245, 
ab97250, ab97260, ab97230). The concentration of plasma samples was calculated by using isotype controls (Biolegend, UK: 401401, 401501, 401201, 401301, 401601) as the initial antigen on the same ELISA plate as samples, with PBS as the primary antibody. Isotype plasma concentrations were then back calculated to find concentrations in whole blood. Calculated concentrations represent lower bounds of the actual blood concentration due to competitive binding between different isotypes within samples.

\subsection{Tumour inoculation}

Mice were challenged with subcutaneous injections of $3 \times 10^{4}$ TUBO cells. 325 Tumours were allowed to grow for 25 days and measured at least twice a week in three orthogonal axes (x, y and $\mathrm{z}$ ). Tumour volumes were calculated as xyz/2.

\subsection{Western Blot}

Samples were diluted in a 1:1 dilution with Laemmli sample buffer (Bio-Rad, USA) with $5 \% \beta$-mercaptoethanol (Sigma Aldrich, UK) before heating to $95^{\circ} \mathrm{C}$ for 5 minutes. Samples consisted of either the recombinant extracellular domain of ErbB-2 protein (Abcam, UK: ab191967) or TUBO cell lysate (as described above). Samples were then run on a pre-cast 4-20\% polyacrylamide gel (BioRad, USA) with 1x Tris-Glycine-SDS running buffer (Bio-Rad, USA) and 160V for 1 hour using a Mini-PROTEAN Tetra Vertical electrophoresis kit (Bio-Rad, USA). Gels were transferred onto a $0.2 \mu \mathrm{m}$ pore size nitrocellulose membrane (Bio-Rad, USA) with 30V overnight using a Mini Trans-Blot Western blotting system (Bio-Rad, USA). Membranes with transferred proteins were blocked with $5 \%$ skimmed milk (Sigma Aldrich, UK) in PBS for 1 hour before being washed with $0.05 \%$ Tween-20 in PBS and incubated with plasma from mice diluted 1:1000 in PBS $0.5 \%$ skimmed milk for 1 hour. Next, membranes were washed with $0.05 \%$ Tween-20 in PBS and incubated with a HRP conjugated anti-mouse IgG antibody raised in goat (R\&D Systems, USA) at a dilution of 1:1000 in PBS $0.5 \%$ skimmed milk for a further hour. Immobilon Western HRP Substrate (Merck Millipore, USA) was used for chemiluminescent detection of protein. 

substrate for 3 minutes. Excess substrate was then drained before exposing the membranes to X-ray films (ThermoFisher, UK) for approximately 10 seconds. Films were developed using an Agfa CP 1000 film processor.

\subsection{Cell death}

Ability of plasma samples, positive for anti-ErbB-2 $266-296$ antibodies, to induce cell death was tested on TUBO cells. Cells were plated onto a 96 well plate at 10,000 cell/well and incubated for 24 hours. The media was then removed and replaced with fresh media containing different dilutions of either PBS, anti-ErbB-2266-296 negative plasma (from pre-treatment bleeds), or antiErbB-2 $266-296$ positive plasma (from $\mathrm{OVA}+\mathrm{E}(\mathrm{O})$ treated mice). Plasma samples started at a 1:10 dilution in PBS and were complement-deactivated by heating to $55^{\circ} \mathrm{C}$ for 30 minutes prior to dilution with media. Cells were then incubated for a further 24 hours before replacement of the media dilutions with fresh media. Cells were then imaged using brightfield microscopy on an Eclipse TI inverted microscope (Nikon Inc, USA) at 10x magnification.

Cells treated with media only and the highest dilutions of PBS, and antiErbB-2 $266-296$ negative and positive plasma were also washed with fresh media and analysed on a Becton Dickson FACSCalibur until 5000 events per sample were collected to measure the amount of debris in the samples $(n=3)$. Data was then analysed using the software FlowJo version 10 (FlowJo LLC, USA).

\subsection{Statistics}

Statistical analysis was performed using R. Cytotoxicity means were compared with one-way ANOVA followed by Tukey's post-test. ELISA results were first tested for normality by Shapiro-Wilks test with a p-value less than 0.05 and thus were analysed using non-parametric tests. Kruskal-Wallis and ConoverIman tests were used to find differences between antibody responses of groups. Differences were considered to be significant when the p-value was less than 0.05. Indicators of statistical significance: $\mathrm{ns}, \mathrm{p}>0.05,{ }^{*}, \mathrm{p}<0.05$; ${ }^{* *} \mathrm{p}<0.01$; $* * *, \mathrm{p}<0.001$. 


\subsection{Formulation and characterisation}

Liposomes were formulated as described in the methods section. Four different liposome formulations were prepared: OVA $_{323-339}$ encapsulating liposomes, denoted '(O)'; liposomes with external ErbB-2 $266-296$, but no OVA $323-339$ 'E()'; liposomes with internal $\mathrm{OVA}_{323-339}$ and external ErbB-2 $266-296$, 'E(O)'; and liposomes with $\mathrm{OVA}_{323-339}$ containing a cysteine residue at the C-terminus externally conjugated, 'Oc()'. Samples of $(\mathrm{O}), \mathrm{E}(\mathrm{)})$ and $\mathrm{E}(\mathrm{O})$ liposomes were used in vaccination studies, while $\mathrm{Oc}()$ liposomes were only used as a control during characterisation. $6.1 \mathrm{mg} / \mathrm{mL}$ phospholipid concentration, with a molarity of $8-9 \mathrm{mM}$ (table $\mathrm{S} 2$. Samples were adjusted to have the same concentrations of ErbB-2 and/or OVA peptide. 


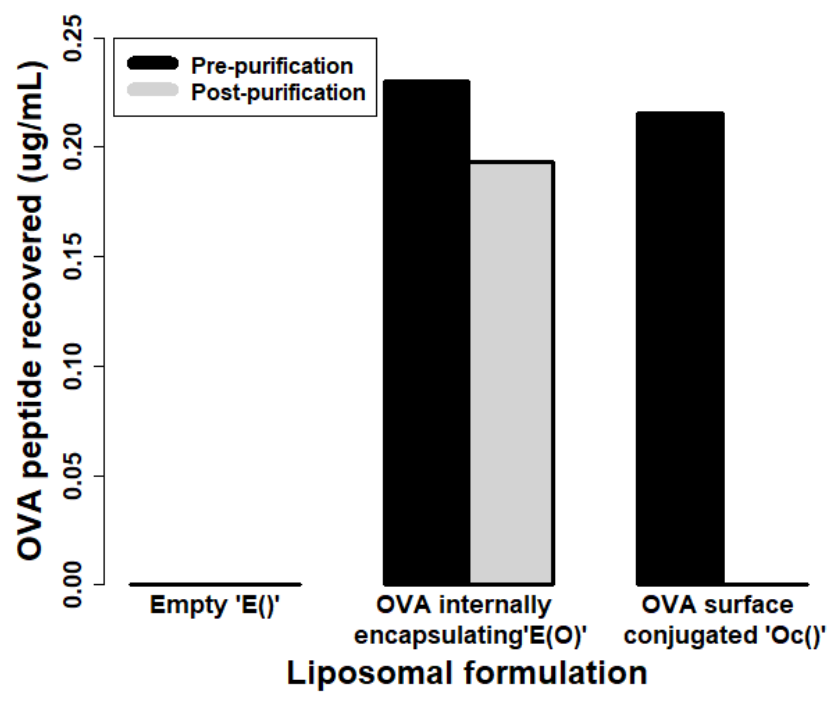

Figure 1: Assessment of the presence and location of OVA peptide using an anti-OVA column. Samples of liposomal formulations were first diluted and then passed through a protein A column primed with anti-OVA $323-339$ antibody to capture available OVA peptide. Resultant spinout from the columns were then assayed by ELISA for OVA peptide concentration. Each bar represents blank corrected mean absorbance of $n=2$ sample wells. $E()$ denotes liposomes surface decorated with ErbB-2 peptide but with no OVA; E $(\mathrm{O})$ denotes OVA peptide encapsulating, ErbB-2 peptide surface decorated liposomes; and Oc() denotes liposomes with an externally conjugated $\mathrm{OVA}_{323-339}$ peptide. The black bar represents the amount of OVA detected in the sample before passage through the anti-OVA column, the grey bar represents the amount of OVA detected in the eluate from the column.

Sample of liposome formulation were diluted and purified by protein A-antiOVA antibody columns. Attachment of liposomes to the column was evidence of externally presented OVA, whilst presence of OVA in the eluate evidenced that the OVA was internal and unable to bind the protein A-anti-OVA antibody (figure 1). No OVA peptide could be detected in the $\mathrm{E}()$ liposomes before or after purification, see 'Empty E()' columns on figure 1. Positive control liposomes with an externally conjugated OVA peptide, Oc(), were not detected in the eluate (i.e. no grey bar), indicating they were efficiently removed by binding to the column. Notably, high levels of OVA was confirmed to be in the sample before its addition to the column(black bar). Use of this positive control 

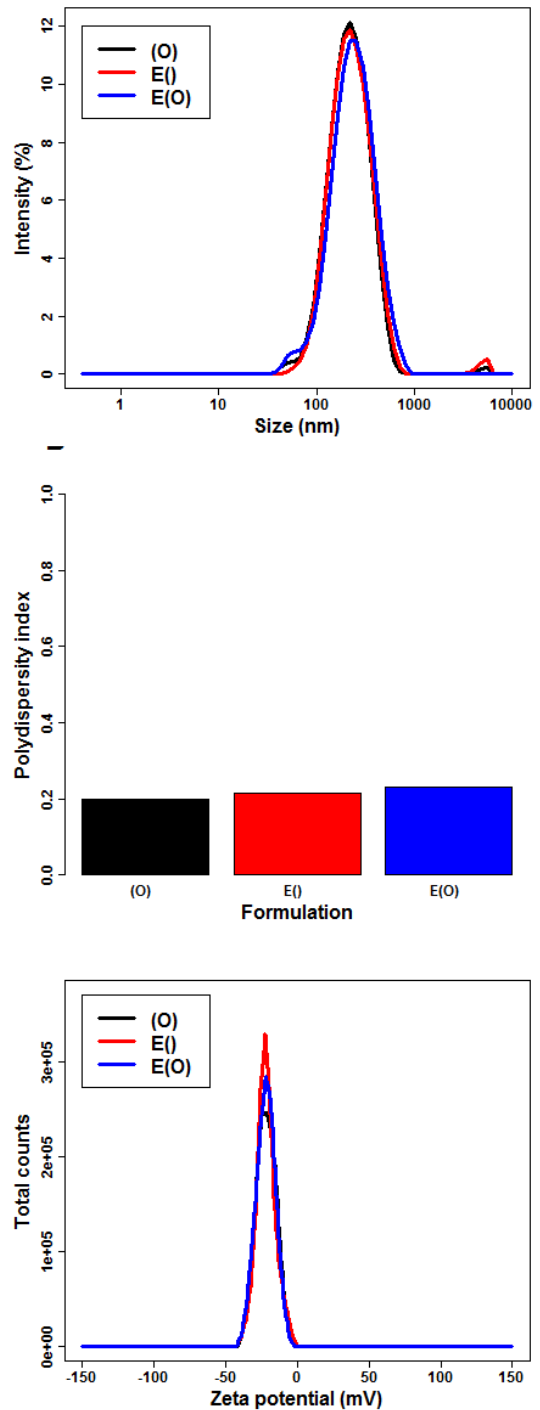

Figure 2: Physciochemical characterisation of liposomes: Size and polydispersity was characterised by dynamic light scattering (DLS), while surface charge was characterised by Zeta potential as described in the methods section. Panel A shows the intensity plot of sizes of liposome samples, panel B shows the polydispersity index of samples, and panel $\mathrm{C}$ shows the frequency plot of sample surface charges. Results were obtained by 3 measurements per sample, made up of 12-14 sub-runs. 
For $\mathrm{E}(\mathrm{O})$ liposomes a similar high level of OVA content was measured in the sample before addition to the column. However, in contrast to the Oc() sample, the level of OVA detected in the eluate was reduced by just 10\%, showing $90 \%$ to be encapsulated and unavailable for binding to the column. The low level of column-binding-available OVA in the sample may be free peptide, peptide associated with the liposome surface or encapsulated peptide released due to disruption of the formulation during its passage through the column. Supplementary table $\mathrm{S} 2$ demonstrates that regardless of the reason for its presence it is likely that almost 1000-fold more ErbB-2 peptide than OVA will be present on the surface of the liposomes, based on quantification of ErbB-2 S2

Liposomal size was measured by DLS. Liposomes were formulated to have an approximate size of $200 \mathrm{~nm}$ so as to be approximately the size of a viral particle $(20-400 \mathrm{~nm})$. (O), E() and $\mathrm{E}(\mathrm{O})$ had average sizes of $191.7 \mathrm{~nm}, 200.7$, and $211.4 \mathrm{~nm}$ respectively (figure 2A). Both formulations had a low polydispersity index showing the liposomes in the samples to be monodisperse (figure 2 B).

Zeta Potential was used to characterise the surface charge of liposomes. All liposomes were made to be anionic, with $(\mathrm{O}), \mathrm{E}(\mathrm{)}$ ) and $\mathrm{E}(\mathrm{O})$ liposomes having surface charges of $-21.8,-20.8$, and $-18.8 \mathrm{mV}$, respectively (figure $2 \mathrm{C}$ ).

Cytotoxicity of liposomes was examined via an MTS assay on human lung carcinoma cells, A549. Cells were cultured with liposomes for 24 hours at varying liposome:media ratios. There was no statistically significant difference in viability for cells receiving any formulation of liposome up to a concentration of $10 \%$ liposomes in media as determined by one-way ANOVA tests at the $\alpha=$ 0.05 confidence level (figure S3.

\subsection{Proof of mechanism}

The proposed mechanism of action for the liposomal vaccine was tested by comparing the ability of $\mathrm{BALB} / \mathrm{c}$ and $\mathrm{FVB} / \mathrm{n}$ mice to generate anti-ErbB$2_{266-296}$ antibodies after vaccination. Mice first received two identical $100 \mu \mathrm{L}$ doses of either PBS or $10 \mu \mathrm{g}$ of OVA peptide, emulsified with immunoadjuvant 


\begin{tabular}{|l|l|l|l|}
\hline $\begin{array}{l}\text { OVA or PBS dose } \\
\text { (Weeks }-4 \text { and }-2)\end{array}$ & $\begin{array}{l}\text { Liposomal } \\
\text { vaccination }\end{array}$ & $\begin{array}{l}\text { Number of } \\
\text { FVB/n mice }\end{array}$ & $\begin{array}{l}\text { Number of } \\
\text { BALB/c mice }\end{array}$ \\
\hline \multirow{2}{*}{ PBS + TMG } & $(\mathrm{O})$ & 5 & 5 \\
\cline { 2 - 4 } & $\mathrm{E}(\mathrm{O})$ & 5 & 5 \\
\hline \multirow{2}{*}{ OVA + TMG } & $\mathrm{E}()$ & 5 & 5 \\
\cline { 2 - 4 } & $\mathrm{E}(\mathrm{O})$ & 5 & 5 \\
\hline
\end{tabular}

Table 1: Number of mice in each group for vaccination study confirming proposed mechanism of action. Identical groups are used for both BALB/c and FVB/n mice. TMG is an immunoadjuvant called TitreMax Gold; OVA is a peptide of Ovalbumin; (O) denotes liposomes encapsulating OVA peptide; E() liposomes surface decorated with ErbB-2 peptide; E(O) OVA peptide encapsulating, ErbB-2 peptide surface decorated liposomes.

TitreMax Gold (TMG) at a 1:1 ratio, two weeks apart to generate pre-existing anti-OVA helper $\mathrm{T}$ cell immunity in some of the mice, as described previously [18. Two weeks after the second OVA or PBS dose, mice were injected with either $\mathrm{OVA}_{323-339}$ encapsulating liposomes, denoted (O); ErbB-2 $266-296$ presenting, empty liposomes, denoted E(); or OVA $_{323-339}$ encapsulating, ErbB266-296 presenting liposomes, denoted $\mathrm{E}(\mathrm{O})$. Identical samples and treatment groups were used for both $\mathrm{BALB} / \mathrm{c}$ and $\mathrm{FVB} / \mathrm{n}$ mice (table 1). Mice in the $\mathrm{PBS}+\mathrm{E}(\mathrm{O})$ group (table 1) lack the non-cognate $\mathrm{CD} 4+\mathrm{T}$ cell populations capable of providing activating signals to $\mathrm{B}$ cells to initiate antibody responses [18, this should, therefore, limit the amount of antibody produced. Similarly, $\mathrm{B}$ cells should not receive activation signals when the pre-existing anti-OVA immunity is present, but the OVA peptide is missing from the liposome construct, as is the case for OVA+E() group.

Weekly plasma samples were collected from both $\mathrm{FVB} / \mathrm{n}$ (figure $3 \mathrm{~A}$ ) and BALB/c (figure 3B) mice, which first showed an antibody response 7 days after vaccination. At 14 days post-vaccination, no statistically significant difference was found between the mean responses of any $\mathrm{FVB} / \mathrm{n}$ mice exposed to any form of ErbB- $2_{266-296}$. This indicates that anti-OVA ${ }_{323-339}$ non-cognate CD4+ T 

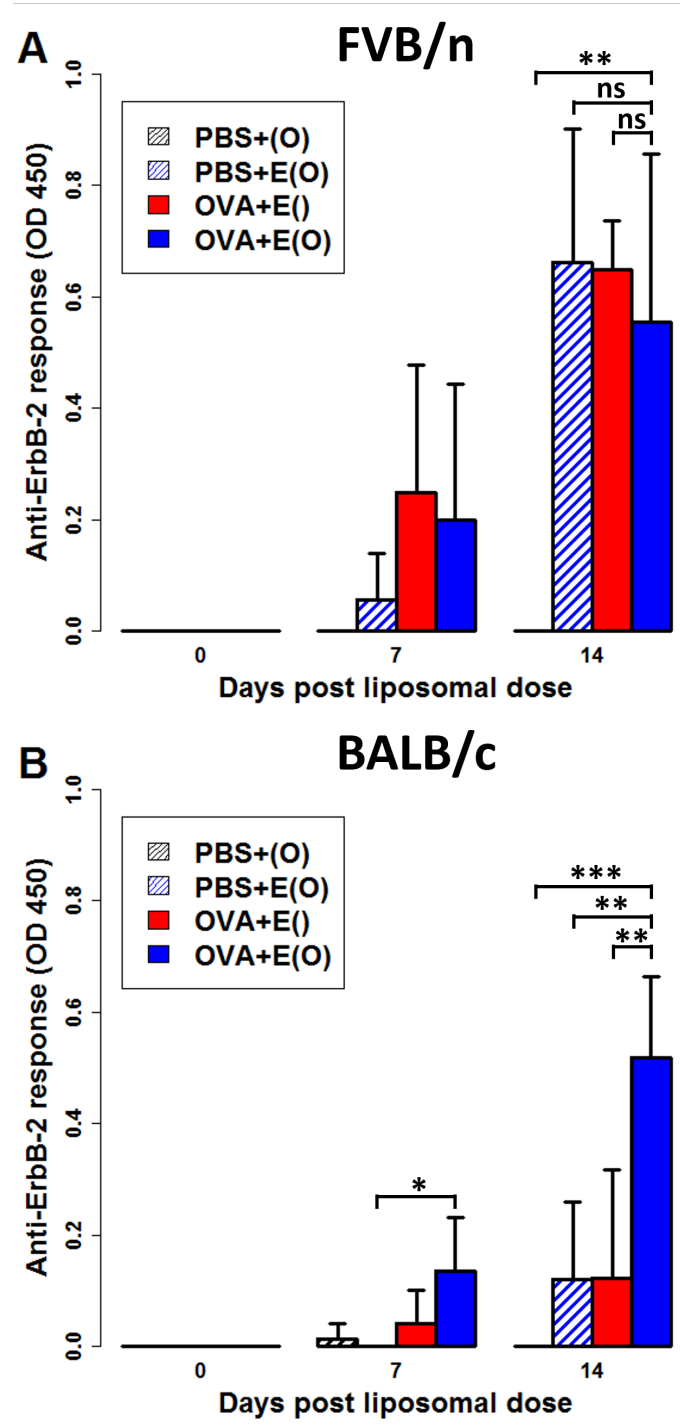

Figure 3: Anti-ErbB-2 IgG responses in FVB/n (Panel A) and BALB/c (Panel B) mice: Plasma samples were taken from the mice on 0,7 , and 14 days post liposomal vaccination and tested by ELISA to detect if the mice had generated an antibody response to the ErbB-2 peptide. Plasma samples were run using a 1:400 dilution. Mice dosed with PBS or OVA peptide are shown with striped or solid bars, respectively. Mean of $n=5$ mice, error bars represent standard deviation. Indicators of statistical significance: $\mathrm{ns}, \mathrm{p}>0.05 ;{ }^{*}, \mathrm{p}<0.05$; ** $\mathrm{p}<0.01 ; * * *, \mathrm{p}<0.001$. 
cells have not played a role in activation of antibody production. In contrast, $\mathrm{BALB} / \mathrm{c}$ mice, at 14 days, showed a significantly $(\mathrm{p}<0.01)$ raised $(4.2$-fold $)$ response in the OVA $+\mathrm{E}(\mathrm{O})$ group, which has pre-existing anti-OVA $323-339 \mathrm{immu}-$ nity and was vaccinated with $\mathrm{E}(\mathrm{O})$ liposomes. Notably, there was no difference between the $\mathrm{PBS}+\mathrm{E}(\mathrm{O})$ group and the $\mathrm{OVA}+\mathrm{E}()$ group, as in both cases noncognate $\mathrm{T}$ cells were unable to produce helper signals to the $\mathrm{B}$ cells.

\subsection{Larger cohort tumour challenge study}

Having confirmed the mechanism of action, the anti-tumour effect of the response generated against ErbB-2 could be tested by challenging immunised mice with TUBO cells shown to overexpress the target (figure S4). Furthermore, this second study on a larger cohort of BALB/c mice permitted the assessment of the necessity of each vaccination component (table $\mathrm{S} 3$ ) and the kinetics of the humoral antibody response.

Mice received two identical doses of either PBS or OVA peptide with immunoadjuvant, Addavax, on weeks -4 and -2 (figure 4A). Then on weeks 0, 1 and 4 mice were injected with identical doses of PBS; free ErbB-2 peptide, denoted $\mathrm{E}$; or liposome formulations $\mathrm{E}()$ or $\mathrm{E}(\mathrm{O})$. Weekly plasma samples were collected

from the day of the first liposomal vaccination which were subsequently tested for anti-ErbB-2 $266-296$ antibody responses. On week 5, mice were challenged with the TUBO tumour cell line. Tumours were allowed to grow for 25 days before sacrifice.

Figure 4 B-H shows the anti-ErbB- $2_{266-296}$ total IgG titres of individual 485 mice over the duration of the experiment. At week 0 (figure 4 B), the day of initial liposomal dose, there was no detectable antibody response showing that the mice do not have a detectable pre-existing humoral IgG response towards the ErbB-2 peptide target. After just 1 week (figure $4 \mathrm{C}$ ), all mice in the OVA+E(O) (solid blue circles) group generated high antibody levels (Geometric mean titre 490 (GMT) of 2467), with the PBS+E(O) (empty blue circles) and OVA+E() (solid red circles) groups also demonstrating a detectable antibody response but with a GMT of 7.3, and 9.5 fold lower than those in the OVA+E(O) group, respectively. 


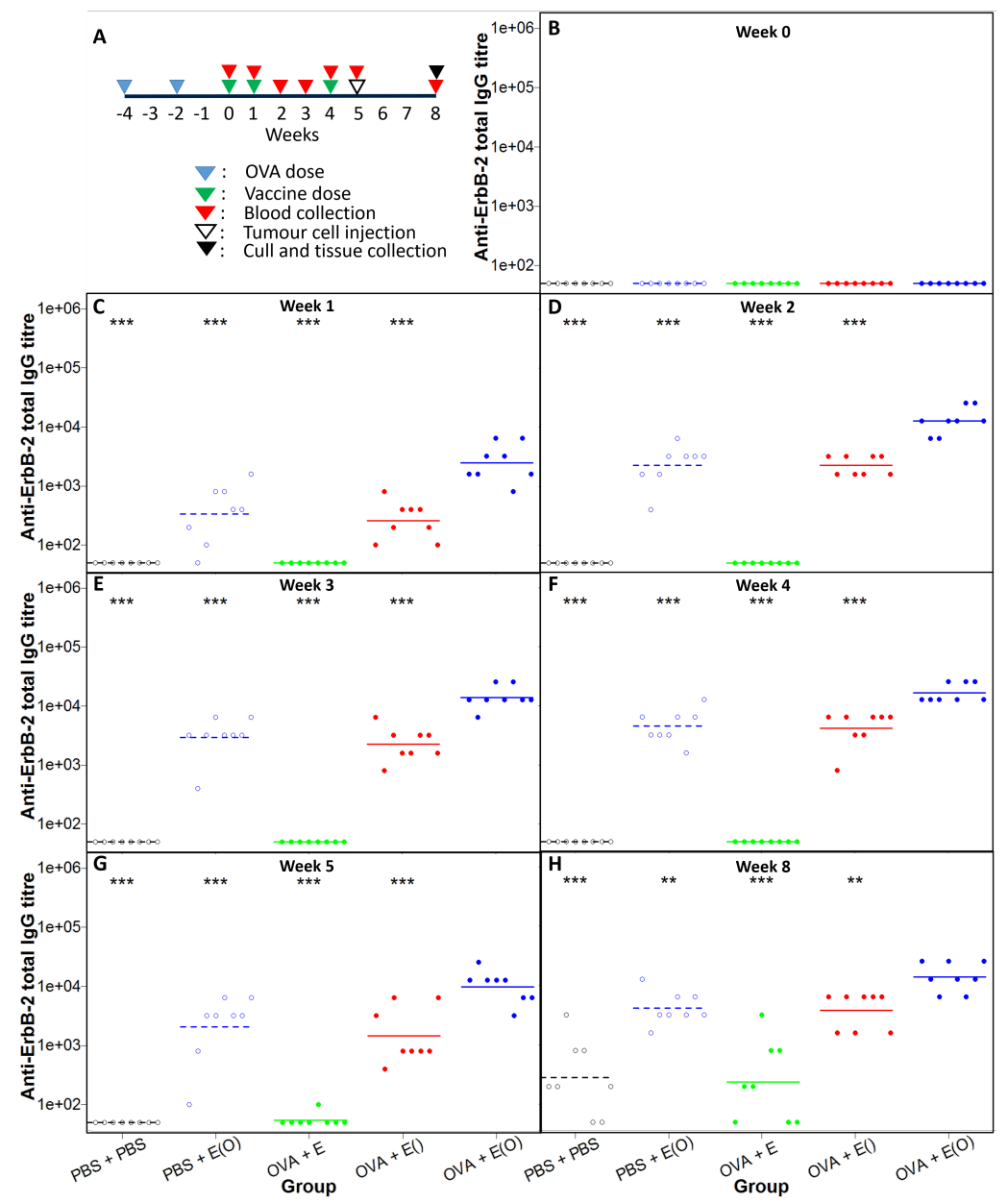

Figure 4: Anti-ErbB-2 IgG titres in BALB/c mice: Weekly plasma samples were taken from mice and tested by ELISA to detect an antibody response to the ErbB-2 peptide. The titre of plasma was defined to be the last dilution tested that gave an absorbance reading above 0.05 after subtraction of the average absorbance and 2 standard deviations of 16 blank wells that received PBS instead of plasma. Panel A shows a timeline of the experiment and panels B-H show weekly titres of individual mice from the day of first liposomal vaccination (Panel B) to cull $($ Panel H). Lines represent geometric means of $n=8$. Vaccines were administered in $100 \mu \mathrm{L}$ doses and those which contained ErbB-2 had a concentration of $100 \mu \mathrm{g} / \mathrm{mL}$ of ErbB-2. Indicators of statistical significance: ns, $\mathrm{p}>0.05 ;{ }^{*}, \mathrm{p}<0.05$; $^{* *} \mathrm{p}<0.01$; ${ }^{* * *}, \mathrm{p}<0.001$, for all groups compared to OVA+E $(\mathrm{O})$ group. 


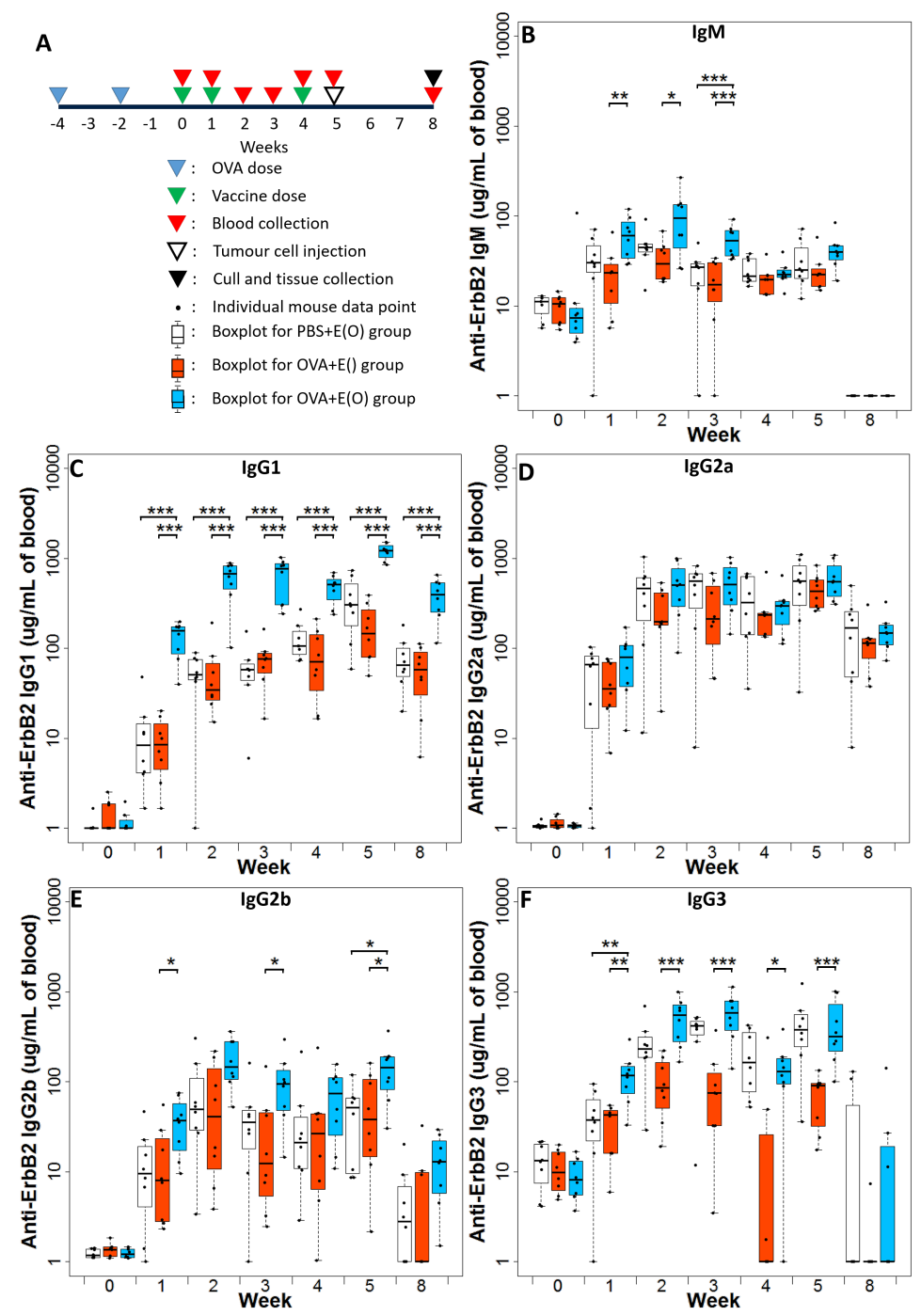

Figure 5: $\operatorname{IgM}$ and $\operatorname{IgG}$ isotype concentrations in the blood of mice in $\mathrm{OVA}+\mathrm{E}(\mathrm{O}), \mathrm{PBS}+\mathrm{E}(\mathrm{O})$, and OVA $+\mathrm{E}()$ groups were quantified by ELISA. Panel A shows a timeline of experiment and a key for the rest of the figure. Panels B, C, D, E, and F show the boxplots of whole blood concentrations of IgM, IgG1, IgG2a, IgG2b and IgG3, respectively. Each boxplot is made from $\mathrm{n}=8$ data points. To avoid zero values for log-scaling on the $\mathrm{y}$-axis, all data points had 1 added to them. Indicators of statistical significance: ns, $\mathrm{p}>0.05$;, $\mathrm{p}<0.05$; ** $\mathrm{p}<0.01$; ***, $\mathrm{p}<0.001$, for all groups compared to OVA $+\mathrm{E}(\mathrm{O})$ group. 


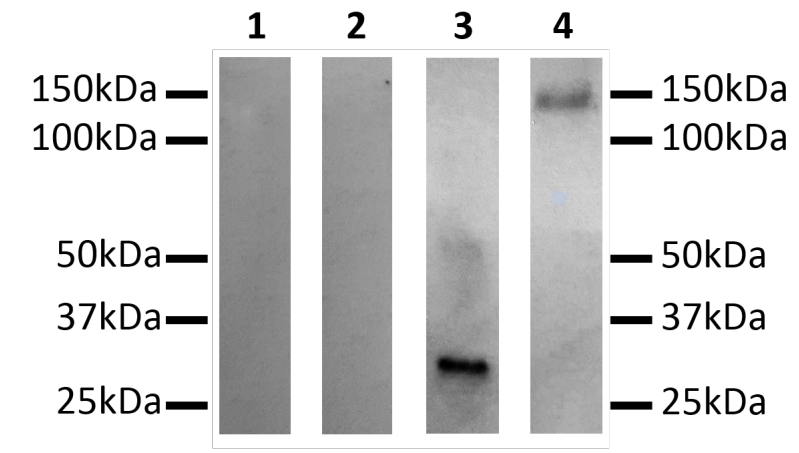

Figure 6: Western blots were used to test the ability of plasma from mice with and without anti-ErbB-2 $266-296$ antibodies to bind to whole ErbB-2 protein on ErbB-2 overexpressing TUBO tumour cells. Lanes 1 and 2 were incubated with a 1:1000 dilution of plasma from mice which had been dosed with PBS and then vaccinated with $(\mathrm{O})$. While lanes 3 and 4 were incubated with a 1:1000 dilution of plasma from mice in the OVA+E $(\mathrm{O})$ group. Lanes 1 and 3 were loaded with the extracellular domain of a recombinant rat ErbB2 protein while lanes 2 and 4 contain TUBO cell lysate. Recombinant ErbB-2 protein used has a molecular weight of $29 \mathrm{kDa}$ while cellular ErbB-2 has an estimated molecular weight of $137 \mathrm{kDa}$. TUBO cells are a mouse mammary carcinoma cell line that overexpress rat ErbB-2.

The speed and level of the response achieved is in accordance with the findings of Hills, et al. 18. At week 1, mice also received their first booster dose. By week 2 495 (figure 4D), one week post first boost, the IgG levels of all liposomal vaccinated mice increased, with both the $\mathrm{PBS}+\mathrm{E}(\mathrm{O})$ and $\mathrm{OVA}+\mathrm{E}()$ vaccinated groups having GMTs 5.7 fold lower than the OVA+E(O) vaccinated group (GMT of 12800). These titres were maintained through to week 4 (figure $4 \mathrm{E}-\mathrm{F}$ ) when the third and final dose was given. At week 5, the third liposomal dose did not appear to have any effect in increasing the antibody levels further (figure 4 G). In summary, this data demonstrates the value of this approach, as only in instances when an encapsulated antigen, with pre-existing immunity towards it, is used, is a rapid and maximal response achieved.

Antibody responses of $\mathrm{PBS}+\mathrm{E}(\mathrm{O}), \mathrm{OVA}+\mathrm{E}()$, and $\mathrm{OVA}+\mathrm{E}(\mathrm{O})$ groups were further characterised by measuring the concentration of each isotype of antiErbB-2antibody in whole blood (figure 5). All groups showed anti-ErbB-2 $266-296$ 
IgM and IgG3 responses prior to initial liposomal vaccination (figure $5 \mathrm{~B}$ and F) but low IgG1, IgG2a and IgG2b levels (figure 5 C-E). Upon first exposure to liposomal vaccine, both groups generated increased anti-ErbB-2 $266-296$ IgM and IgG subtype antibody levels, with stronger class switching to IgG1 occurring in the OVA $+\mathrm{E}(\mathrm{O})$ group. The effect of the booster liposomal vaccines can be seen to increase the concentrations of all IgM and IgG subtypes. Anti-ErbB-2 $266-296$ IgM levels of all three groups remained relatively consistant throughout the duration of the experiment, with a slight increase in concentration after the second liposomal vaccination (figure $5 \mathrm{~B}$ ). The combination of pre-existing anti-OVA immunity and liposomally-encapsulated OVA peptide, led to consistently higher anti-ErbB-2 266-296 IgG1 levels and initially higher IgG3 levels (figure 5 C,F).

The ErbB- $2_{266-296}$ sequence contains two cysteine residues and a third cysteine residue was included to the $\mathrm{C}$ terminus to allow conjugation to maleimidebearing liposomes. It is possible that a proportion of ErbB- $2_{266-296}$ peptides are conjugated via cysteine residues contained within the peptide sequence, rather than at the $\mathrm{C}$ terminus. To ensure that ErbB-2 presented on liposomes was capable for eliciting antibody responses that recognised ErbB-2 in it's native conformation, antibodies generated against ErbB-2 peptide were tested for their ability to bind to ErbB-2 protein from cell lysate by Western blot. Lanes 1 and 2 in figure 6 were probed with plasma from mice in the PBS+PBS group, while lanes 3 and 4 were stained with plasma from mice in the OVA+E(O) group. Lanes 1 and 3 contain the extracellular domain of a recombinant rat ErbB2 protein while lanes 2 and 4 contain TUBO cell lysate. The recombinant ErbB-2 protein used has a molecular weight of $29 \mathrm{kDa}$ while cellular ErbB-2 has an estimate molecular weight of $137 \mathrm{kDa}$. In lane 3 , a band can be seen at approximately $30 \mathrm{kDa}$ which corresponds to the extracellular domain of a recombinant rat ErbB-2 protein. This band does not appear in lane 1 indicating that the OVA dosed $\mathrm{E}(\mathrm{O})$ treatment produces antibodies that specifically 535 target the desired ErbB- $2_{266-296}$ peptide sequence. Similarly, a band can be seen at approximately $140 \mathrm{kDa}$ in TUBO lysate stained when probed with antiErbB-2 $266-296$ antibodies (lane 4 ) but not when anti-ErbB-2 $266-296$ antibodies 
are absent (lane 2) showing the vaccine generated anti-ErbB-2 antibodies are able to bind to ErbB-2 protein from cells.

Figure 6 evidences the ability of antibodies raised to bind the ErbB-2 target. Before challenging mice with tumour cells it was important to validate whether such binding would lead to cell death in vitro. Therefore, plasma from mice, both positive and negative for anti-ErbB-2 $266-296$ antibodies, was tested in vitro for ability to induce cell death by adding plasma to a monolayer of TUBO cells. Figure 7 shows that increasing the concentration of anti-ErbB- $266-296$ antibody positive plasma from $\mathrm{OVA}+\mathrm{E}(\mathrm{O})$ vaccinated mice increases the amount of in vitro TUBO cell death evident by microscopy, whereas addition of equivalent concentrations of antibody negative plasma or PBS does not impact markedly on cell morphology. This was supported by flow cytometric analysis of cells 24hours post exposure which showed that for a monolayer of TUBO cells exposed to only media $82.2 \pm 2.1 \%$ of events were live at 24 hours, while cells challenged with PBS or anti-ErbB- $2_{266-296}$ negative plasma had a marginal decrease in the proportion of live cells $(68.9 \pm 1.0 \%$ and $65.8 \pm 0.7 \%$ events, respectively) (figure 8. Cells treated with anti-ErbB-2 $266-296$ positive plasma, however, showed that only $4.0 \pm 0.2 \%$ of events were live (figure 8). Notably this plasma was heat-treated and there were no leukocytes present so this only accounts for the direct (i.e. non ADCC or CDC) mediated death that could potentially be achieved in vivo [29].

Once the level and nature of the antibody response generated had been characterised, the response was tested to see if it would provide protection against tumour challenge (figure 9). The take rate of the tumours did not reach $100 \%$, with 3 mice having no signs of palpable tumours at the time of cull. The incomplete take rate was unlikely to be due to treatment as 2 of the mice without tumours were in the $\mathrm{PBS}+\mathrm{PBS}$ group, while the remaining mouse was in the $\mathrm{OVA}+\mathrm{E}(\mathrm{O})$ group. With the exception of the PBS+PBS group, tumour growth profiles largely aligned with measured antibody responses (figure 4), however, there was high within-group variability. As a result no meaningful difference could be observed. While not group-dependent, a linear relationship between 


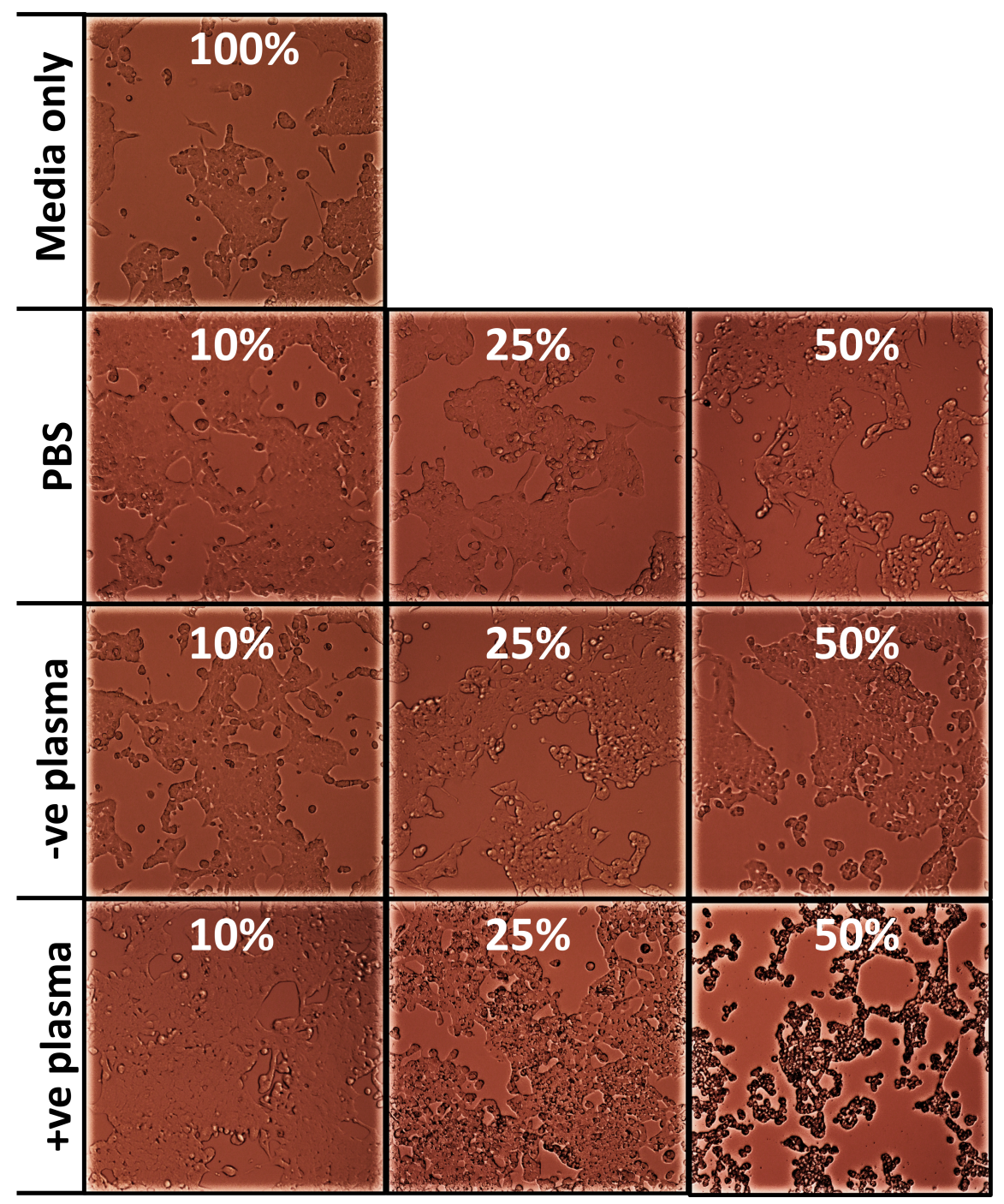

Figure 7: Cell death of TUBO cells incubated for 24 hourswith varying dilutions of PBS or anti-ErbB-2 $266-296$ negative (-ve plasma) or positive (+ve plasma) obtained from prevaccination or $\mathrm{OVA}+\mathrm{E}(\mathrm{O})$ vaccinated mice TUBO cells were plated in 96 well plates for 24 hours before exposure to dilutions of either negative plasma. which was pooled plasma from pre-vaccine blood samples, or positive plasma, which was pooled plasma from mice in the OVA $+\mathrm{E}(\mathrm{O})$ group taken at week 4 (i.e. before mice were implanted with TUBO cells). Starting plasma samples were at a 1:10 dilution and complement-deactivated. Images shown are representative of 5 replicate samples. 


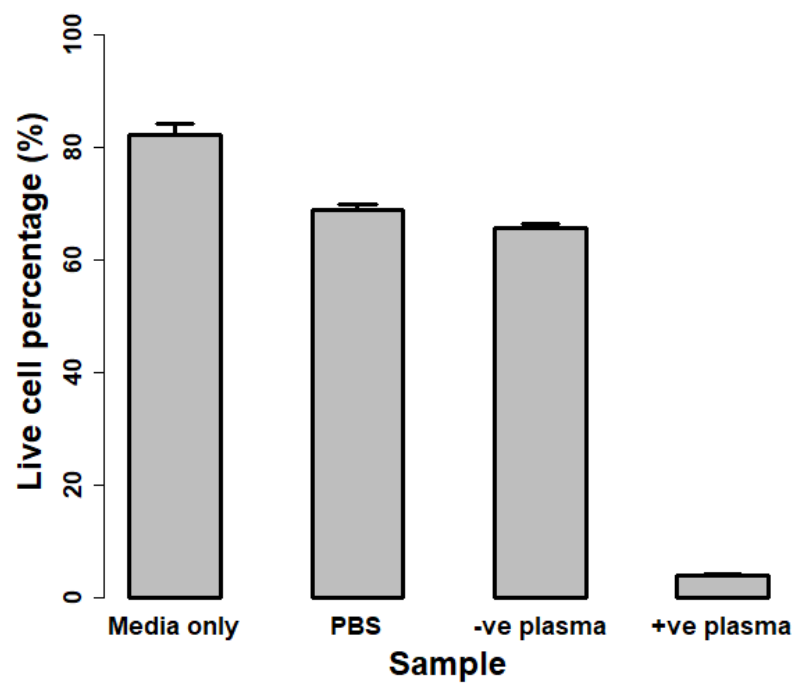

Figure 8: Impact of mouse serum on in vitro TUBO cell monolayer viability as assayed by flow cytometry. Cells were incubated with media only; a 1:1 dilution of PBS in media; or antiErbB-2 266-296 negative (-ve plasma) or positive (+ve plasma) plasma for 24 hours. Negative plasma was pooled plasma from pre-vaccine blood samples, while positive plasma was pooled plasma from mice in the OVA $+\mathrm{E}(\mathrm{O})$ group before they were implanted with TUBO cells. Plasma samples were complement-deactivated and diluted 1:1 with fresh media and thus had a final dilution of 1:20. Data represents the average $(n=3)$ proportion of events contained within live-cell gating, \pm 1 standard deviation.

the weights of tumour and spleens at cull was seen, suggesting the presence of an immune response against the tumours.

At week 8, the 4 largest tumours in each group were resected, along with the corresponding mouse's spleen for cellular analysis by flow cytometry. Resected tumours were processed into single-cell suspensions and examined for ErbB-2 expression on non-immune cells (CD45-) and the presence of tumour-infiltrating 575 lymphocytes. Meanwhile, isolated splenocytes were tested for B cell populations $(\mathrm{B} 220+\mathrm{CD} 19+)$, helper $\mathrm{T}$ cell populations (CD3+CD4+), and cytotoxic T cell populations $(\mathrm{CD} 3+\mathrm{CD} 8+)$. Figure $\mathrm{S} 5$ shows the gating strategy for single-cell suspensions of tumour and spleen samples. Images shown in figure 55 are the result of concating 20 samples. The majority of live cells isolated from the 

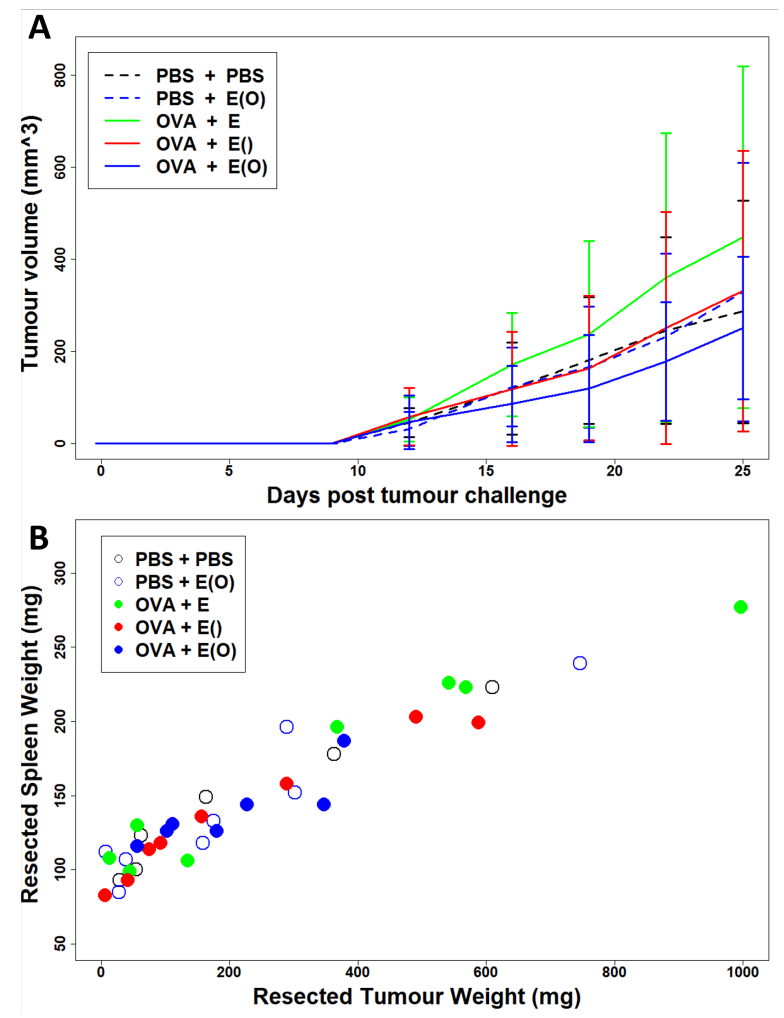

Figure 9: Mice were subcutaneously injected with $3.4 \times 10^{4}$ TUBO tumour cells and checked daily for the presence of tumours. Tumours were measured twice a week with callipers in three orthogonal directions ( $x, y$, and $z$ ) with volume calculated as xyz/2. Panel A shows the average tumour growth curve, bars representing $95 \%$ confidence intervals. Panel B shows the comparison of the weight of tumour and spleen resected from mice at cull. The take rate of the tumours did not reach $100 \%$, with 3 mice having no signs of palpable tumours at the time of cull. Tumours were not evident in three mice at the time of sacrifice and therefore these data represent $n=6$ in the PBS+PBS group, $n=7$ in the OVA $+E(O)$, and $n=8$ in the $\mathrm{PBS}+\mathrm{E}(\mathrm{O}), \mathrm{OVA}+\mathrm{E}(\mathrm{O}), \mathrm{OVA}+\mathrm{E}()$ groups.

tumours are ErbB-2-ve CD45-ve perhaps indicating they are stromal cells or have lost ErbB-2 expression (figures S4 and S5A). Analysis of the cell population with poor or no viability (i.e. medium or intense zombie violet staining) showed no difference between groups.

Figure 10A shows the average percentage populations of cell types success- 

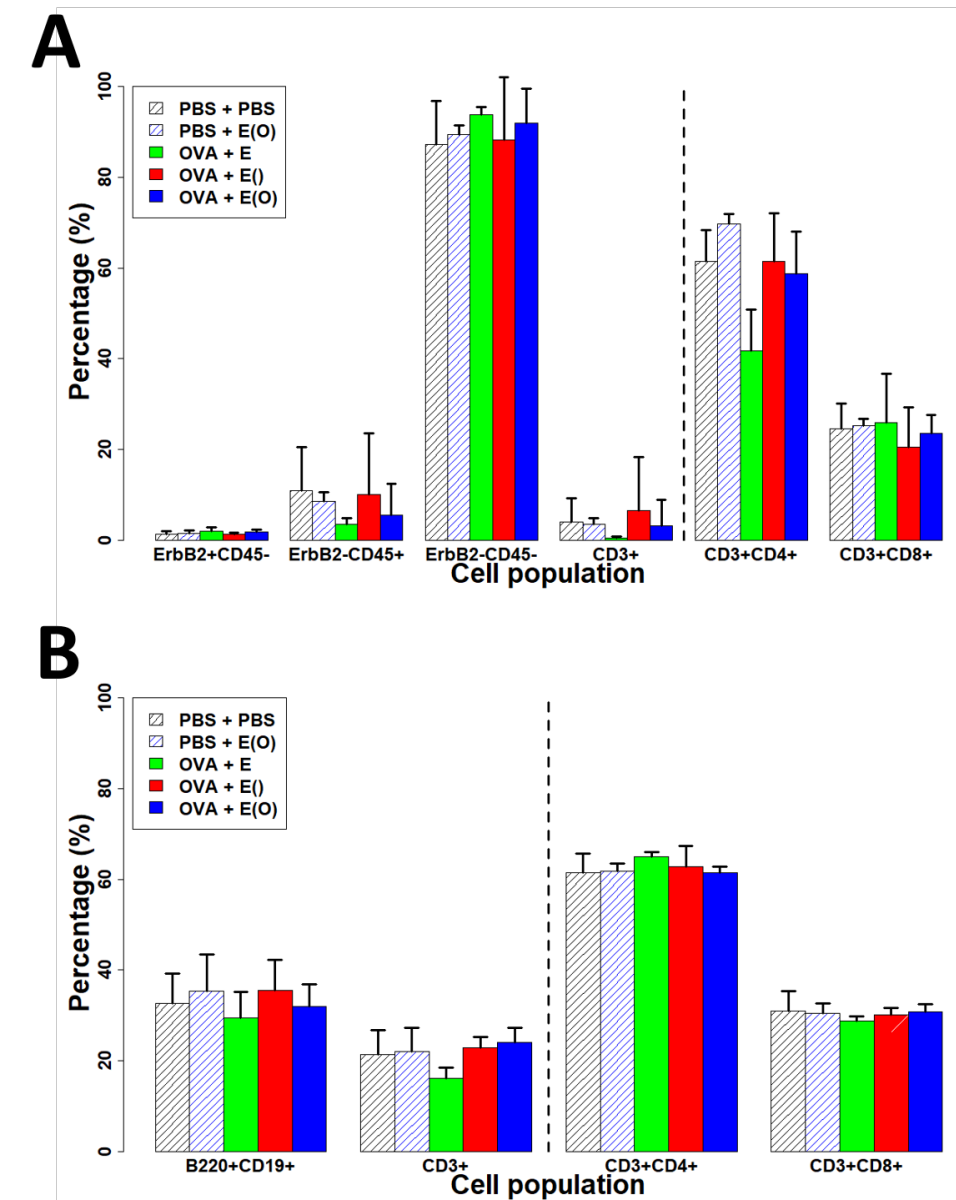

Figure 10: Bar chart showing the average percentage populations of cell types $( \pm 1$ standard deviation) isolated from resected tumours (panel A) and spleens (panel B). Tumours and spleens were resected from 4 mice in each group with the largest tumours and processed into single-cell suspension as described in section 2.12 Data represents the percentage of all nondebris, singlet, live events gated for. Data for CD3+CD4+ and CD3+CD8+ are presented as percentages of CD3+ gated events. Gating strategy for flow cytometry of isolated single-cell suspensions from resected tumours and spleens of mice is given in figure $\mathrm{S5}$

fully isolated alive from resected tumours for each group. As seen in the pooled samples of figure S5A, a very small proportion of live cells were ErbB-2+CD45(0.8-3.0\%). The majority of isolated live cells (67-98\%) were ErbB-2-ve and 
CD45-ve and so were likely mainly consisting of tumour cells that have lost their ErbB-2 expression, fibroblasts and other tumour co-opted host cells. This may, therefore, be the reason for the lack of any significant difference between the tumour growth curves of any treatment group (figure 91). The decision to assay the largest tumours from each group was necessitated by processing losses but ultimately may have selected the least therapy responsive mice.

The cellular immunological profile was explored by looking at splenocytes to see if the treatment had an effect on the number of $\mathrm{B}$ and $\mathrm{T}$ cell populations (figure 10 B). No differences could be seen in the proportion of circulating B $(\mathrm{B} 220+\mathrm{CD} 19+)$ or $\mathrm{T}$ cells (CD3+) between groups, nor for the proportion of helper (CD4+CD8-) and cytotoxic (CD4-CD8+) T cells (figure 10B).

While there were no group-dependencies on the cellular populations analysed, a negative linear trend between the spleen weight and some of the cell populations was seen (figure $\mathrm{S}$ S6 . Sample cell numbers were first adjusted by the weight of the resected tissue prior to staining. Figure $\mathbf{S} 6$ shows that the increase in size of the spleen resulted in a lower proportion of singlets being isolated from the samples. The relationships in figures $\mathrm{S} 56 \mathrm{C}$ and D indicate that the increase in spleen weight in response to the increase in tumour size (figure 9C) is not due to an increase in the number of B cells or T cells. Therefore, this increase in size may be due to an increase in other leukocyte populations.

\section{Discussion}

This study describes a novel development of the liposomal vaccine platform described by Hills, et al. 18 to target the cancer antigen ErbB-2 which is overexpressed in 15 - 30\% of all breast cancers, as well as in many other cancers such as ovarian, renal, colon and lung [3. Many patients with ErbB-2 overexpressing tumours have previously shown an ability to mount a weak immune response towards this antigen, showing that it is possible to overcome the self-tolerance associated with it 4, 5. Trastuzumab, a monoclonal humanised antibody that targets ErbB-2, licensed in 1998, was one of the first target-specific drugs to be 
used in the clinic [30]. A large proportion of treatment regimes for ErbB-2 overexpressing tumours now include Trastuzumab due to its favourable therapeutic index [31, 32, 33]. Pertuzumab, licensed in 2012, is a more recent addition to the options for treatment of ErbB-2 overexpressing cancers. Pertuzumab is a humanised monoclonal antibody which it binds to a region of ErbB-2 that inhibits ErbB-2 dimerisation with ErbB-3, rather than ErbB-2 homodimerisation like Trastuzumab 34, 35. The peptide sequence used/targeted in the studies reported here, was originally described by Allen, et al. 24, and mimics the Pertuzumab binding region, and hence appeared to be a good target. The antibodies generated in response to the vaccine should, therefore, provide the same therapy as Pertuzumab, by inhibiting ErbB-2 dimerisation with ErbB-3.

The peptide described by Allen, et al., mimicking the binding region of Pertuzumab has been used in a vaccination approach in combination with a peptide mimicking the Trastuzumab binding region found by Garrett, et al. [36] in an ongoing phase I trial. Each peptide was conjugated to independent measles virus fusion protein helper epitopes. This trial has recently completed its first stages [37, 9]. The objective of the first stage of the trial was focused on establishing the safety profile of the vaccine and ascertaining any dose-limiting toxicities, as such it was open to all patients with metastatic, incurable solid tumour malignancies, regardless of ErbB-2 expression [9. The second stage of the trial, which is currently ongoing, is applying the optimised vaccine dose to vaccinate patients with ErbB-2 overexpressing tumours (NCT01376505). The first stage of the trial found the vaccine elicited sustained ErbB-2-specific humoral responses in a majority of the patients across the different dose levels 9 . Of the 35 evaluable patients, 19 had progressive disease, 14 had stable disease, and 2 showed partial responses, though this limited response may be due to enrolled patients having non-ErbB-2 overexpressing tumours [9]. One of the patients with a partial response continued to receive 6 month booster doses for 6453.5 years.

One concern with the generation of ErbB-2 antibody responses would be the risk of cardiotoxicity, a majore adverse effect of Trastuzumab and Pertuzumab 
therapy. Costa, et al. performed a meta-analysis of several ErbB-2 vaccines and found that their cardiotoxicity profile compared favourably to those of both Trastuzumab and Pertuzumab 38. Regardless, future pre-clinical and clinical work with vaccine strategies eliciting anti-ErbB-2 antibodies should assess for symptomatic and asympomatic reductions in ventricular ejection fraction.

A vaccine would enable the patient to produce their own antibodies towards the target and generate immunological memory for a sustained response. Identification of cancer antigens has opened up many new possibilities for the development of effective cancer immunotherapies [39]. A notable portion of cancer immunotherapy has been directed to the development of cancer vaccines, this is in large part due to the success of anti-viral vaccines. Peptide vaccines target an immunogenic region on a tumour antigen to initiate an immune response against the target protein. A large number of peptide-based vaccines are conjugated to a second helper peptide or protein that is known to elicit a strong immune response, so as to cause a stronger response to the target antigen. However, this approach can result in the immune response against the helper peptide or protein dominating over the response against the target antigen [40, 41, 42]. By spatially segregating the helper peptide, as we do in our vaccine platform [18, the immune response generated is exclusively targeted towards the target peptide itself.

Here, liposomes were formulated to address the hypothesis of non-cognate $\mathrm{T}$ cell support for B cell production of antibodies against the ErbB-2 cancer antigen. Physiochemical characterisation showed their size, polydispersity, protein content, surface charge, and cytotoxicity levels to be suitable. Free nonencapsulated OVA peptide was shown to be successfully separated from liposomes by size exclusion, an essential step in ensuring the desired mechanism of action. The concentration of OVA present in liposome samples after all purification steps was found to be approximately $4 \mu \mathrm{g} / \mathrm{mL}$. This is much lower than the initial concentration of peptide added to the dried lipids $(1 \mathrm{mg} / \mathrm{mL})$ due to dilution factors in the purification steps and inherent poor passive loading efficiency of liposomes. Hills, et al., used a similar liposomal formulation method 
and saw similarly low levels of OVA encapsulation [18. This poor-loading is widely-recognised problem and should be addressed in the development of future liposomal vaccine strategies. Several techniques have been proposed including hydration of lipids with buffer containing the peptide to be loaded, in the presence of $30 \%$ ethanol, which increased loading efficiency 5-fold compared to hydration with peptide containing buffer alone [43. Freeze-thaw cycles increase loading efficiency [44, however, with the risk of maleimide hydrolysation, this method may not be well suited to the current liposome formulation. The concentration of cholesterol incorporated into the liposome structure also plays a role, as while cholesterol increases the structural stability of liposomes, it also has been shpwn to inhibit liposomal loading [45]. Liposomes were designed to be anionic to prevent them from escaping endosomal degradation once engulfed by $B$ cells 16. The mechanism of action requires vaccine particles to be degraded once engulfed so that B cells can present peptide fragments on their MHC II proteins for helper $\mathrm{T}$ cell recognition. Zeta potential measurement showed them to have a net negative surface charge around $-20 \mathrm{mV}$. DLS showed their size to be approximately $200 \mathrm{~nm}$ in diameter, which falls within the expected range for a virus particle $(20-400 \mathrm{~nm})$. Larger liposomes $(>500 \mathrm{~nm})$ tend to have a much shorter in vivo half-life due to phagocytosis [46]. It has also been indicated that small liposomes $(20-200 \mathrm{~nm})$ can freely traffic into draining lymph nodes [47]. Carrasco, et al. showed that after administration, $200 \mathrm{~nm}$ particles coated with protein, accumulated in the boundary of the lymph node follicles where B cells initially encounter their cognate antigen [48. Liposomes were also found to be non-cytotoxic in vitro.

The proposed mechanism of action for the vaccination platform was first tested by comparing the anti-target antibody responses generated by $\mathrm{FVB} / \mathrm{n}$ and $\mathrm{BALB} / \mathrm{c}$ mice (figure 3 . FVB/n mice, which are unable to present the helper OVA peptide on the surface of their B cells [25, 26], generated similar anti-ErbB-2 $266-296$ total IgG responses with or without the help of non-cognate CD4+ T cells (figure $3 \mathrm{~A}$ ). BALB/c mice, which are able to present the OVA peptide on their $\mathrm{B}$ cell surface for $\mathrm{T}$ cell recognition, showed an increase in 
anti-ErbB- $2_{266-296}$ total IgG levels only when mice had pre-existing anti-OVA immunity and were vaccinated with the full vaccine construct, $\mathrm{E}(\mathrm{O})$ (figure 3 B). This provided further exquisite proof that the mechanism proposed by Hills, et al. and developed here is capable of generating increased antibody levels by non-cognate T-helper cell activation of B cells, activated by a liposomal vector with precise spatial separation of $\mathrm{B}$ cell receptor and T-helper cell peptides.

The mechanism of action, kinetics and necessity for each component of the vaccine was then explored for its influence on anti-ErbB- $2266-296$ antibody responses in a tumour challenge study with BALB/c mice. It was found that mice with pre-existing anti-OVA immunity, achieved by OVA dosing, which were then vaccinated with $\mathrm{E}(\mathrm{O})$ liposomes, generated rapid (within 7 days), substantially $(7.3$-fold $)$ and significantly $(\mathrm{p}<0.001)$ raised antibody titres compared to all other groups (figure 4). Of particular note was the similarity between the $\mathrm{PBS}+\mathrm{E}(\mathrm{O})$ group and the $\mathrm{OVA}+\mathrm{E}()$ group as neither of these could recruit non-cognate CD4+ $\mathrm{T}$ cells to help activate $\mathrm{B}$ cells and in turn stimulate increased antibody production (figure 4).The isotype profiles of the $\mathrm{PBS}+\mathrm{E}(\mathrm{O})$, $\mathrm{OVA}+\mathrm{E}()$ and $\mathrm{OVA}+\mathrm{E}(\mathrm{O})$ groups were then characterised. Each individual isotype interacts with the immune system differently [49] and also differently than their human counterparts [50, 51]. IgM is the first antibody isotype produced after initial antigen exposure [52]. The IgM responses of all mice increased after vaccination and remained relatively constant until week 8 when none could be detected, which is likely the result of a steady decline between weeks 5 and cull (figure 5B). Mice showed consistently higher IgG1 class-switching when they had pre-existing anti-OVA immunity, from just one week after initial exposure to ErbB-2 peptide (figure $5 \mathrm{C}$ ). IgG1 is the same isotype as the pre-clinical studies version of Pertuzumab, prior to humanisation [53]. Therefore, this particular anti-ErbB- $2_{266-296}$ antibody isotype should not only bind to the same region of the protein as Pertuzumab, but also interact with the immune system identically. Indeed, none of the pre-clinical studies of Pertuzumab demonstrated the antibodies ability to induce ADCC or CDC [54]. Production of IgG1 is increased in the presence of $\mathrm{T}$ cell-dependent $\mathrm{B}$ cell activation, such is the case for the pro- 
posed mechanism of action here [50. Its contribution to protective immunity is largely unclear, as in mice it is unable to fix complement and only engages with the inhibitory Fc $\gamma$ RIIb receptor of effector cells [50]. IgG1's main role is therefore believed to be in limiting inflammatory responses and neutralising target molecules from binding their receptor [50]. All of the isotyped groups showed high levels of IgG2a and IgG2b class switching which is, therefore, unlikely due to the mechanism of action and may in fact simply be due to the adjuvanting effect of the liposome present. IgG2a and IgG2b both have similar functions in mice with IgG2a levels linked to an increase in cytotoxic $\mathrm{T}$ cell levels and IgG2b levels linked to $\mathrm{T}$ cell independent $\mathrm{B}$ cell activation [50]. Both isotypes are able to fix complement and have strong interactions with Fc $\gamma \mathrm{R}$ effector cells [50]. Though the combination of encapsulated OVA peptide and pre-existing OVA immunity generated increased anti-ErbB-2 $266-296$ IgG3 levels early on in the experiment, mice in the $\mathrm{PBS}+\mathrm{E}(\mathrm{O})$ group soon generated comparable IgG3 levels to the OVA $+\mathrm{E}(\mathrm{O})$ group, while the OVA $+\mathrm{E}()$ group continuously had lower levels (figure $5 \mathrm{~F}$ ). IgG3 is the earliest produced IgG isotype and is able to fix complement well which leads to a cascade of inflammatory responses [50].

After challenge with rat ErbB-2 overexpressing TUBO tumour cells, antiErbB-2 $266-296$ IgG levels could be detected by ELISA in mice not previously exposed to the ErbB-2 peptide, confirming the peptide is representative of the epitope exposed on the tumour cells (figure $4 \mathrm{G}-\mathrm{H}$ ). A Western blot was used to further confirm that the peptide is representative of the epitope on TUBO cells, by probing with plasma samples from a high-responding mouse in the $\mathrm{OVA}+\mathrm{E}(\mathrm{O})$ group and a pre-vaccination plasma sample of the $\mathrm{PBS}+(\mathrm{O})$ group (figure 6).

Plasma samples positive for anti-ErbB-2 $266-296$ antibodies, were subsequently shown to induce in vitro cell death (figures 7 and 8). This is likely due to the bloackage of ErbB-2/ErbB-3 dimer formation, and thus a reduction of ErbB-2 activation. Cuello, et al. previously demonstrated that anti-ErbB-2 therapy could induce apoptosis in ErbB-2 overexpressing cell lines, but not in cell lines with low levels of ErbB-2 expression [55]. This may explain why plasma positive 
for anti-rat-ErbB-2 could induce apoptosis in TUBO cells in vitro despite its co-expression of mouse ErbB-2 in these cells. A primary function of ErbB-2 is suppression of apoptosis to enhance cell survival, thus inhibition of its activation will increase cellular apoptosis [56, 57]. This, therefore, demonstrates the ability for the vaccine-induced immune response to inhibit the growth of ErbB-2 overexpressing tumour cell lines.

Despite achieving the desired specificity of the antibody response and the high anti-ErbB-2 antibody titres, no statistically significant differences in tumour growth were seen (figure 91. The less than $100 \%$ take rate in this study was likely due to insufficient cells being administered to challenge the mice rather than the vaccination treatment (figure 9A) [28. To probe if successful mechanism of action was being concealed by tumour growth and structure heterogeneity, mice with the 4 largest tumours from each group, at cull, had their tumours and spleens resected and processed into single-cell suspensions to analyse the cellular populations contained within them. The live CD45-ve cells were found to have lost their overexpression of ErbB-2 in all of the tumours, giving reason as to why the anti-ErbB- $2_{266-296}$ humoral responses had no marked effect in inhibiting the tumour take rate or growth rate (figures S5 and 10. TUBO cells are a transgenic cell line spontaneously developed by a BALB/c mouse transformed to express the rat ErbB-2 oncogene [28]. The loss of rat ErbB-2 expression may, therefore, be due to in vivo selective pressures increasing the burden on cells expressing this transgene, resulting in the loss of its expression in favour of its already existing mouse ErbB-2 protein. Plasma samples positive for anti-ErbB-2 $266-296$ antibodies, were subsequently shown to induce in vitro cell death (figures 7 and 8). This is likely due to the blockade of ErbB-2/ErbB-3 dimer formation, and thus a reduction of ErbB-2 activation. The discrepancy between in vitro and in vivo inhibitions may be due to differing amounts of anti-ErbB- $2_{266-296}$ antibodies present in the vicinity of the cells. Whereas in vitro studies in a monolayer permit simple access of antibodies to target cells, the combination of the binding site barrier and the lack of convection across tumours leads to restricted movement of antibody molecules 
into and throughout 3D tumour masses. This ultimately, allows the tumour cells in vivo more time to adapt to the selective pressures present. It is clear that further optimisation of the formulation, dosing stategy and model will be needed to reveal the full potential of the system. This particular application of the approach ultimately seeks to address the breaking of tolerance. Hence, in future studies, it would also be useful to perform a set of studies in Her-2/Neu (neu-N)-transgenic mice as these represent a clinically relevant model of breast cancer and recapitulate immunotolerance to ErbB-2 [58].

\section{Conclusion}

Our study has demonstrated the ability of a liposomal-based vaccine, which spatially segregates target and helper peptides, to generate a rapid, high-titre, isotype-switched, humoral immune response against the cancer antigen ErbB-2,

${ }_{815}$ by repurposing pre-existing non-cognate CD4+ T helper cells. These generated antibodies were subsequently demonstrated to be able to induce cell death of an ErbB-2 overexpressing cell line in vitro.

\section{Acknowledgments}

J. W. acknowledges funding from the University of Oxford, the EPSRC and BBSRC Centre for Doctoral Training in Synthetic Biology (grant EP/L016494/1) and the Defence Science and Technology Laboratory (DSTL) (grant DSTLX1000102376). R. C. is supported by the EPSRC under the Oxford Centre for Drug Delivery Devices OXCD3 (Grant EP/L024012/1).

\section{Author contributions}

825 JW - planned and performed experiments, analysed data and wrote and edited the paper. RC - supervised the project, planned experiments, analysed data and wrote and edited the paper. PK - helped perform experiments. AM helped perform experiments. TH - developed the concept, helped plan experiments, edited the paper. DS supervised the project, helped plan experiments, 
830 the paper.

\section{Declaration of interest}

The authors declare no competing interests.

\section{References}

${ }_{835}^{\text {口 }}[1]$ W. H. Organization, Immunization coverage, http://www.who.int/ features/factfiles/immunization/en/, accessed: 26/06/2018.

q [2] J. Wallis, D. P. Shenton, R. C. Carlisle, Novel approaches for the design, delivery and administration of vaccine technologies, Clinical \& Experimen-

口 tal Immunology 196 (2) (2019) 189-204. arXiv:https://onlinelibrary. wiley.com/doi/pdf/10.1111/cei.13287, doi:10.1111/cei.13287. URL https://onlinelibrary.wiley.com/doi/abs/10.1111/cei.13287

[3] N. Iqbal, N. Iqbal, Human epidermal growth factor receptor 2 (HER2) in cancers: overexpression and therapeutic implications, Molecular biology international 2014.

845

[4] M. L. Disis, E. Calenoff, G. McLaughlin, A. E. Murphy, W. Chen, B. Groner, M. Jeschke, N. Lydon, E. McGlynn, R. B. Livingston, R. Moe, M. A. Cheever, Existent t-cell and antibody immunity to her-2/neu protein in patients with breast cancer, Cancer Research 54 (1994) 16-20.

[5] M. L. Disis, S. M. Pupa, J. R. Gralow, R. Dittadi, S. Menard, M. A. ${ }_{850}$ Cheever, High-titer her-2/neu protein-specific antibody can be detected in patients with early-stage breast cancer, Journal of Clinical Oncology 15 (1997) 3363-3367. doi:10.1200/JC0.1997.15.11.3363.

[ [6] J. K. Liu, The history of monoclonal antibody development progress, remaining challenges and future innovations, Annals 855 of Medicine and Surgery 3 (4) (2014) 113 - 116. doi:https: 
//doi.org/10.1016/j.amsu.2014.09.001

प

URL http://www.sciencedirect.com/science/article/pii/ S2049080114000624

[7] P. D. Bryson, X. Han, N. Truong, P. Wang, Breast cancer vaccines delivered by dendritic cell-targeted lentivectors induce potent antitumor immune responses and protect mice from mammary tumor growth, Vaccine 35 (43) (2017) 5842-5849.

[8] M. Antonilli, H. Rahimi, V. Visconti, C. Napoletano, I. Ruscito, I. G. Zizzari, S. Caponnetto, G. Barchiesi, R. Iadarola, L. Pierelli, et al., Triple peptide vaccination as consolidation treatment in women affected by ovarian and breast cancer: clinical and immunological data of a phase I/II clinical trial, International journal of oncology 48 (4) (2016) 1369-1378.

[9] T. Bekaii-Saab, R. Wesolowski, D. H. Ahn, C. Wu, A. Mortazavi, M. B. Lustberg, B. Ramaswamy, J. Fowler, L. Wei, J. Overholser, P. T. Kaumaya, Phase 1 immunotherapy trial with घ two chimeric her-2 b-cell peptide vaccines emulsified in montanide isa 720vg and nor-mdp adjuvant in advanced solid tumors, Clinical Cancer ResearcharXiv:http://clincancerres.aacrjournals.org/ content/early/2019/03/02/1078-0432.CCR-18-3997.full.pdf, doi: 10.1158/1078-0432.CCR-18-3997.

URL http://clincancerres.aacrjournals.org/content/early/2019/ 03/02/1078-0432. CCR-18-3997

[10] N. Norton, N. Fox, C.-A. McCarl, K. S. Tenner, K. Ballman, C. L. Erskine, B. M. Necela, D. Northfelt, W. W. Tan, C. Calfa, et al., Generation of HER2-specific antibody immunity during Trastuzumab adjuvant therapy associates with reduced relapse in resected HER2 breast cancer, Breast Cancer Research 20 (1) (2018) 52.

[11] J. Jasinska, S. Wagner, C. Radauer, R. Sedivy, T. Brodowicz, C. Wiltschke, H. Breiteneder, H. Pehamberger, O. Scheiner, U. Wiedermann, et al., In- 
hibition of tumor cell growth by antibodies induced after vaccination with peptides derived from the extracellular domain of Her-2/neu, International journal of cancer 107 (6) (2003) 976-983.

[12] U. Wiedermann, C. Wiltschke, J. Jasinska, M. Kundi, R. Zurbriggen, E. Garner-Spitzer, R. Bartsch, G. Steger, H. Pehamberger, O. Scheiner, et al., A virosomal formulated Her-2/neu multi-peptide vaccine induces Her-2/neu-specific immune responses in patients with metastatic breast cancer: a phase i study, Breast cancer research and treatment 119 (3) (2010) 673-683.

[13] R. A. Schwendener, Liposomes as vaccine delivery systems: a review of the recent advances, Theraputic advances in vaccines 2 (2014) 159-182. doi:10.1177/2051013614541440.

[14] C. R. Alving, Z. Beck, G. R. Matyas, M. Rao, Liposomal adjuvants for human vaccines, Expert opinion on drug delivery 13 (6) (2016) 807-816.

[15] D. S. Watson, A. N. Endsley, L. Huang, Design considerations for liposomal vaccines: Influence of formulation parameters on antibody and cellmediated immune responses to liposome associated antigens, Vaccine 30 (2012) 2256-2272. doi:10.1016/j.vaccine.2012.01.070.

[16] S. Simões, A. Filipe, H. Faneca, M. Mano, N. Penacho, N. Düzgünes, M. P. de Lima, Cationic liposomes for gene delivery, Expert Opinion on Drug Delivery 2 (2) (2005) 237-254, pMID: 16296751. arXiv:https://doi. org/10.1517/17425247.2.2.237, doi:10.1517/17425247.2.2.237. URL https://doi.org/10.1517/17425247.2.2.237

[17] G. R. Matyas, A. V. Mayorov, K. C. Rice, A. E. Jacobson, K. Cheng, M. R. Iyer, F. Li, Z. Beck, K. D. Janda, C. R. Alving, Liposomes containing monophosphoryl lipid a: a potent adjuvant system for inducing antibodies to heroin hapten analogs, Vaccine 31 (26) (2013) 2804-2810. 
[18] T. Hills, P. G. Jakeman, R. C. Carlisle, P. Klenerman, L. E. Seymour, R. Cawood, A rapid-response humoral vaccine platform exploiting preexisting non-cognate populations of anti-vaccine or anti-viral cd4 $+\mathrm{t}$ helper cells to confirm b cell activation, PLOS One 11 (2016) e0166383. doi: 10.1371/journal.pone.0166383.

[19] M. Bröker, F. Berti, J. Schneider, I. Vojtek, Polysaccharide conjugate vaccine protein carriers as a "neglected valency"-potential and limitations, Vaccine 35 (25) (2017) 3286-3294.

920 [20] L. Chen, D. B. Flies, Molecular mechanisms of t cell co-stimulation and co1 inhibition, Nature reviews immunology 13 (2013) 227-242. doi:10.1038/ nri3405,

[21] B. Ludewig, F. Barchiesi, M. Pericin, R. M. Zinkernagel, H. Hengartner, R. A. Schwendener, In vivo antigen loading and activation of dendritic cells via a liposomal peptide vaccine mediates protective antiviral and antitumour immunity, Vaccine 19 (2013) 23-32. doi:10.1016/S0264-410X (00) 00163-8.

[22] L. J. Cruz, F. Rueda, L. Simón, B. Cordobilla, F. Albericio, J. C. Domingo, Liposomes containing ny-eso-1/tetanus toxoid and adjuvant peptides targeted to human dendritic cells via the fc receptor for cancer vaccines, Nanomedicine 9. doi:10.2217/nnm.13.66.

[23] F. Wimmers, N. De Haas, A. Scholzen, G. Schreibelt, E. Simonetti, M. J. Eleveld, H. M. Brouwers, M. Beldhuis-Valkis, I. Joosten, M. I. De Jonge, et al., Monitoring of dynamic changes in Keyhole Limpet Hemocyanin (KLH)-specific B cells in KLH-vaccinated cancer patients, Scientific reports 7 (2017) 43486.

[24] S. D. Allen, J. T. Garrett, S. Rawale, A. L. Jones, G. Phillips, G. Forni, J. C. Morris, R. G. Oshima, P. T. P. Kaumaya, Peptide vaccines of the her-2/neu dimerization loop are effective in inhibiting mammary tumor 
growth in vivo, The Journal of Immunology 179 (2007) 472-482. doi: 10.4049/jimmunol.179.1.472.

[25] G. Johnsen, S. Elsayed, Antigenic and allergenic determinants of ovalbumin-III. MHC Ia-binding peptide (OA 323-339) interacts with human and rabbit specific antibodies, Molecular Immunology 27 (9) (1990) 821 827. doi:https://doi.org/10.1016/0161-5890(90)90147-R

口 URL http://www.sciencedirect.com/science/article/pii/ $016158909090147 \mathrm{R}$

[26] G. E. Osman, M. C. Hannibal, J. P. Anderson, S. R. Lasky, W. C. Ladiges, L. Hood, FVB/N (H2q) mouse is resistant to arthritis induction and exhibits a genomic deletion of T-cell receptor V beta gene segments, Immunogenetics 49 (10) (1999) 851-859. doi:10.1007/s002510050564.

URL https://doi.org/10.1007/s002510050564

[27] J. Francis Szoka, D. Papahadjopoulos, Comparative properties and methods of preparation of lipid vedicles (liposomes), Annual Review of Biophysics and Bioengineering 9 (1980) 467-508. doi:10.1146/annurev.bb. 09.060180 .002343 .

[28] S. Rovero, A. Amici, E. D. Carlo, R. Bei, P. Nanni, E. Quaglino, P. Porcedda, K. Quaglino, P. Porcedda, K. Boggio, A. Smorlesi, P.-L. Lollini, L. Landuzzi, M. P. Colombo, M. Giovarelli, P. Musiani, G. Forni, Dna vaccination against rat her-2/neu p185 more effectively inhibits carcinogenesis than transplantable carcinomas in transgenic balb/c mice, The

प Journal of Immunology 165 (2000) 5133-5142. doi:10.4049/jimmunol. 165.9.5133,

[29] D. L. Ludwig, D. S. Pereira, Z. Zhu, D. J. Hicklin, P. Bohlen, Monoclonal antibody therapeutics and apoptosis, Oncogene 22 (56) (2003) 9097.

[30] S. M. Pupa, E. Tagliabue, S. Menard, A. Anichini, Her-2: A biomarker at the crossroads of breast cancer immunotherapy and molecular medicine, Journal of Cellular Physiology 205 (2005) 10-18. doi:10.1002/jcp. 20387. 
[31] R. Whitfield, J. Kollias, P. D. Silva, H. Zorbas, G. Maddern, Use of

[32] R. Webster, J. Abraham, N. Palaniappan, A. Caley, B. Jasani, P. BarrettLee, Exploring the use and impact of adjuvant trastuzumab for her2-

[36] J. T. Garrett, S. Rawale, S. D. Allen, G. Phillips, G. Forni, J. C. Morris, P. T. P. Kaumaya, Novel engineered trastuzumab conformational epi- 
topes demonstrate in vitro and in vivo antitumor properties against her-

[37] P. T. Kaumaya, A paradigm shift: Cancer therapy with peptide-based bcell epitopes and peptide immunotherapeutics targeting multiple solid tumor types: Emerging concepts and validation of combination immunotherapy, Human vaccines \& immunotherapeutics 11 (6) (2015) 1368-1386.

[38] R. Costa, S. Zaman, S. Sharpe, I. Helenowski, C. Shaw, H. Han, H. Soliman, B. Czerniecki, A brief report of toxicity end points of her2 vaccines for the treatment of patients with her2+ breast cancer, Drug design, development and therapy 13 (2019) 309.

[39] S. A. Rosenberg, Progress in human tumour immunology and immunotherapy, Nature 411 (2001) 380-384. doi:10.1038/35077246.

[40] C. C. Peeters, A.-M. Tenbergen-Meekes, J. T. Poolman, M. Beurret, B. J. Zegers, G. T. Rijkers, Effect of carrier priming on immunogenicity of saccharide-protein conjugate vaccines, Infection and Immunity 59 (1991) 3504-3510. doi:10.1038/nm1216.

[41] M. P. Schutze, C. Leclerc, M. Jolivet, F. Audibert, L. Chedid, Carrierinduced epitopic suppression, a major issue for future synthetic vaccines., Journal of Immunology 135 (1985) 2319-2322.

[42] K. Pobre, M. Tashani, I. Ridda, H. Rashid, M. Wong, R. Booy, Carrier priming or suppression: understanding carrier priming enhancement of anti-polysaccharide antibody response to conjugate vaccines, Vaccine 32 (2014) 1423-1430. doi:10.1038/nm1216.

[43] S. Shariat, A. Badiee, M. R. Jaafari, S. A. Mortazavi, Optimization of a method to prepare liposomes containing her2/neu-derived peptide as a vaccine delivery system for breast cancer, Iranian journal of pharmaceutical research: IJPR 13 (Suppl) (2014) 15. 
[44] A. P. Costa, X. Xu, D. J. Burgess, Freeze-anneal-thaw cycling of unilamellar liposomes: effect on encapsulation efficiency, Pharmaceutical research 31 (1) (2014) 97-103.

[45] A. Deniz, A. Sade, F. Severcan, D. Keskin, A. Tezcaner, S. Banerjee, Celecoxib-loaded liposomes: effect of cholesterol on encapsulation and in vitro release characteristics, Bioscience reports 30 (5) (2010) 365-373.

[46] M. L. Immordino, F. Dosio, L. Cattel, Stealth liposomes: review of the basic science, rationale, and clinical applications, existing and potential, International journal of nanomedicine 1 (3) (2006) 297.

[49] A. K. Abbas, K. M. Murphy, A. Sher, Functional diversity of helper T lymphocytes, Nature 383 (6603) (1996) 787.

[47] V. Manolova, A. Flace, M. Bauer, K. Schwarz, P. Saudan, M. Bachmann, a Nanoparticles target distinct dendritic cell populations according to their \. Size, European Journal of Immunology 38 (5) (2008) 1404-1413. arXiv: https://onlinelibrary.wiley.com/doi/pdf/10.1002/eji.200737984, doi:10.1002/eji.200737984. URL https://onlinelibrary.wiley.com/doi/abs/10.1002/eji. 200737984

[48] Y. R. Carrasco, F. D. Batista, B cells acquire particulate antigen in 1 a macrophage-rich area at the boundary between the follicle and the subcapsular sinus of the lymph node, Immunity 27 (1) (2007) 160 - 171. doi:https://doi.org/10.1016/j.immuni.2007.06.007 URL http://www.sciencedirect.com/science/article/pii/ S1074761307003342

50] A. M. Collins, Igg subclass co-expression brings harmony to the quartet model of murine igg function, Immunology and cell biology 94 (10) (2016) 949-954. 
[51] G. Vidarsson, G. Dekkers, T. Rispens, Igg subclasses and allotypes: from structure to effector functions, Frontiers in immunology 5 (2014) 520.

[55] M. Cuello, S. A. Ettenberg, A. S. Clark, M. M. Keane, R. H. Posner,

[52] S.-C. Choi, H. Wang, L. Tian, Y. Murakami, D.-M. Shin, F. Borrego, H. C. Morse, J. E. Coligan, Mouse IgM Fc receptor, FCMR, promotes B cell development and modulates antigen-driven immune responses, The Journal of Immunology 190 (3) (2013) 987-996.

[53] B. M. Fendly, M. Winget, R. M. Hudziak, M. T. Lipari, M. A. Napier, A. Ullrich, Characterization of murine monoclonal antibodies reactive to either the human epidermal growth factor receptor or HER2/neu gene product, Cancer research 50 (5) (1990) 1550-1558.

[54] J. Baselga, A new anti-erbb2 strategy in the treatment of cancer: Prevention of ligand-dependent erbb2 receptor heterodimerization, Cancer Cell 2 (2) (2002) 93 - 95. doi:https://doi.org/10.1016/S1535-6108(02) 00098-3

URL http://wwW.sciencedirect.com/science/article/pii/ S1535610802000983

M. M. Nau, P. A. Dennis, S. Lipkowitz, Down-regulation of the ErbB-2 receptor by trastuzumab (herceptin) enhances tumor necrosis factor-related apoptosis-inducing ligand-mediated apoptosis in breast and ovarian cancer cell lines that overexpress ErbB-2, Cancer Research 61 (12) (2001) 4892-4900. arXiv:http://cancerres.aacrjournals.org/content/61/ 12/4892.full.pdf.

URL http://cancerres . aacrjournals .org/content/61/12/4892

[56] R. L. Carpenter, H.-W. Lo, Regulation of apoptosis by HER2 in breast cancer, Journal of carcinogenesis \& mutagenesis 2013 (Suppl 7).

[57] J. Mineo, A. Bordron, I. Quintin-Roue, S. Loisel, K. Ster, V. Buhe, N. Lagarde, C. Berthou, Recombinant humanised anti-HER2/neu anti- 
body (herceptin®) induces cellular death of glioblastomas, British journal of cancer 91 (6) (2004) 1195.

[58] R. T. Reilly, M. B. C. Gottlieb, A. M. Ercolini, J.-P. H. Machiels, C. E. Kane, F. I. Okoye, W. J. Muller, K. H. Dixon, E. M. Jaffee, Her$10852 /$ neu is a tumor rejection target in tolerized her-2/neu transgenic mice,

口 Cancer Research 60 (13) (2000) 3569-3576. arXiv:https://cancerres. aacrjournals.org/content/60/13/3569.full.pdf

URL https://cancerres . aacrjournals . org/content/60/13/3569 


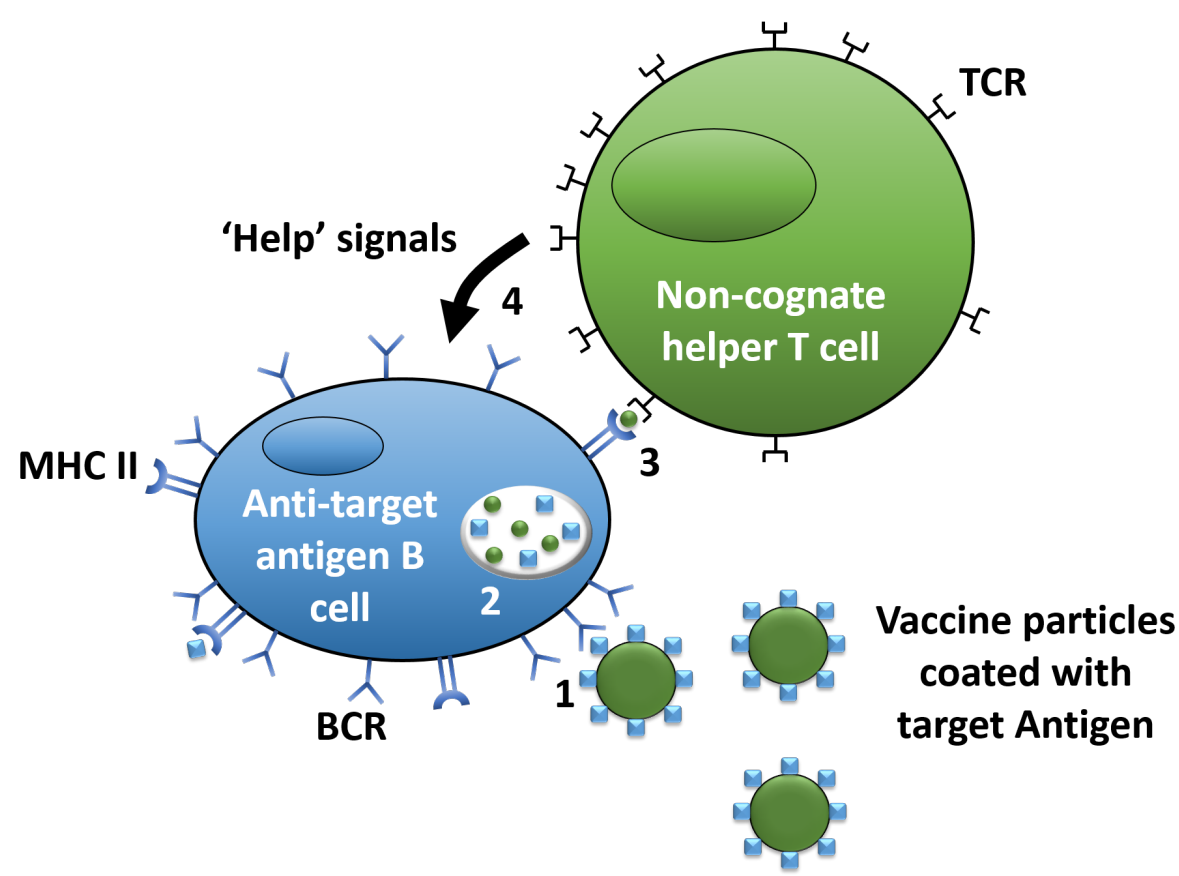

Figure S1: Proposed mechanism of action for Hills, et al. vaccine platform. (1) B cells with specific B cell receptor (BCR) bind to target antigen. (2) B cells engulf and digest vaccine particles and present epitopes on MHC class II. (3) CD4+ T helper cells bind to presenting MHC class II with their specific T cell receptor (TCR). (4) Non-cognate T cells provide helper signals to stimulate antibody production, specific for the target antigen. 


\begin{tabular}{|c|c|c|c|}
\hline Panel & Stain & Purpose & Dilution \\
\hline \multirow{3}{*}{$\begin{array}{l}\text { Tumour } \\
\text { Panel } 1\end{array}$} & Zombie Violet $^{1}$ & Viability stain & $1: 500$ \\
\hline & ErbB-2 - AF $488^{2}$ & Target expression & $1: 1000$ \\
\hline & $\mathrm{CD} 45.2-\mathrm{PE}-\mathrm{Cy} 7^{3}$ & Leukocyte population & $1: 1000$ \\
\hline \multirow{4}{*}{$\begin{array}{l}\text { Tumour } \\
\text { Panel } 2\end{array}$} & Zombie Violet $^{1}$ & Viability stain & $1: 500$ \\
\hline & CD3e - AF488 ${ }^{1}$ & $\mathrm{~T}$ cell population & $1: 100$ \\
\hline & CD4 - PerCp-Cy5.5 $5^{4}$ & CD4+ T cell subpopulation & $1: 1000$ \\
\hline & $\mathrm{CD} 8-\mathrm{APC}-\mathrm{Cy} 7^{4}$ & $\mathrm{CD} 8+\mathrm{T}$ cell subpopulation & $1: 1000$ \\
\hline \multirow{4}{*}{$\begin{array}{l}\text { Spleen Panel } \\
1\end{array}$} & Zombie Violet ${ }^{1}$ & Viability stain & $1: 1000$ \\
\hline & $\mathrm{CD} 3 \mathrm{e}-\mathrm{AF} 488^{1}$ & $\mathrm{~T}$ cell population & $1: 100$ \\
\hline & CD4 - PerCp-Cy5. $5^{4}$ & $\mathrm{CD} 4+\mathrm{T}$ cell subpopulation & $1: 1000$ \\
\hline & $\mathrm{CD} 8-\mathrm{APC}-\mathrm{Cy} 7^{2}$ & CD8+ T cell subpopulation & $1: 500$ \\
\hline \multirow{3}{*}{$\begin{array}{l}\text { Spleen Panel } \\
2\end{array}$} & Zombie Violet ${ }^{1}$ & Viability stain & $1: 1000$ \\
\hline & $\mathrm{B} 220-\mathrm{PE}-\mathrm{Cy} 7^{1}$ & B cell population & $1: 500$ \\
\hline & $\mathrm{CD} 19-\mathrm{APC}^{1}$ & B cell population & $1: 1000$ \\
\hline
\end{tabular}

Table S1: List of staining panels used for flow cytometry of cells extracted from tissue samples. Dilutions were optimised for each tissue type in preliminary studies. ${ }^{1}$ : Biolegend, USA; ${ }^{2}$ : Novus Biologicals, USA; ${ }^{3}$ : Invitrogen, USA; ${ }^{4}$ : eBioscience, USA. 


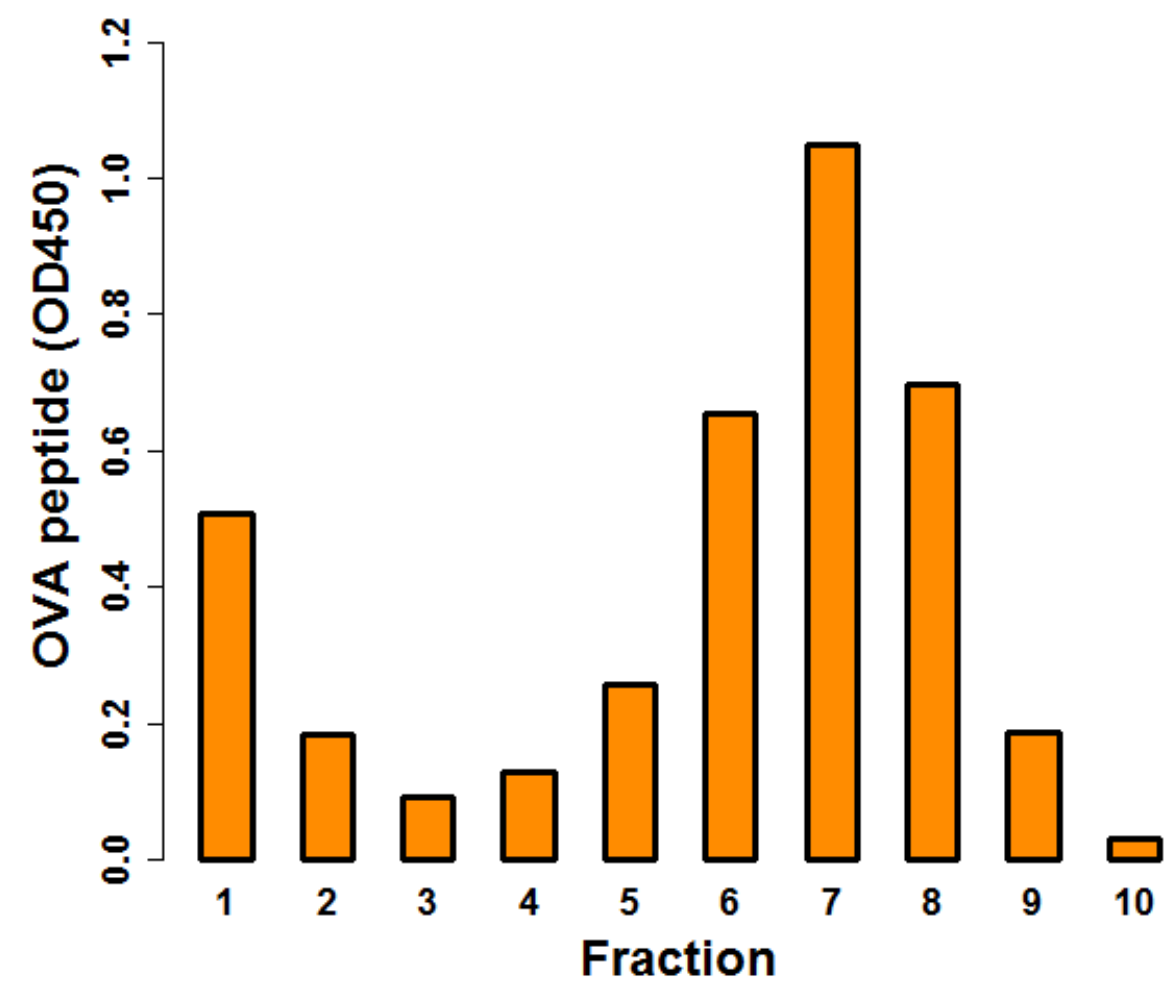

Figure S2: Purification of liposomes: Liposomes were passed through size exclusion columns and collected into $1 \mathrm{~mL}$ fractions to purify away unencapsulated OVA peptide. Visual inspection showed fractions 1 and 2 to be opaque identifying them as liposome containing (data no shown). Fractions were assayed for OVA peptide content using an enzyme-linked immunosorbant assay (ELISA) (see methods section), only fractions from OVA encapsulating formulations gave absorbance readings above background. Each bar represents blank corrected mean absorbance of $\mathrm{n}=2$ sample wells. 


\begin{tabular}{|l|l|l|l|l|}
\hline Formulation & $\begin{array}{l}\text { OVA }_{323-339} \\
(\mu \mathrm{g} / \mathrm{mL})\end{array}$ & $\begin{array}{l}\text { ErbB-2 } 266-296 \\
(\mu \mathrm{g} / \mathrm{mL})\end{array}$ & $\begin{array}{l}\text { Phospholipid } \\
\text { concentration } \\
(\mathrm{mg} / \mathrm{mL})\end{array}$ & $\begin{array}{l}\text { Phospholipid } \\
\text { molarity }(\mathrm{mM})\end{array}$ \\
\hline$(\mathrm{O})$ & 4 & 0 & 6.1 & 9.0 \\
\hline $\mathrm{E}()$ & 0 & 929 & 5.8 & 8.5 \\
\hline $\mathrm{E}(\mathrm{O})$ & 5 & 892 & 5.6 & 8.3 \\
\hline
\end{tabular}

Table S2: Protein and phospholipid concentrations incorporated into liposomal formulations as found by ELISA and phospholipid quantification assay. (O) denoted liposomes encapsulating OVA peptide; $\mathrm{E}()$, liposomes surface decorated with ErbB-2 peptide; and $\mathrm{E}(\mathrm{O})$, OVA peptide encapsulating, ErbB-2 peptide surface decorated liposomes.

\begin{tabular}{|l|l|l|}
\hline $\begin{array}{l}\text { OVA or PBS dose } \\
\text { (Weeks }-4 \text { and }-2)\end{array}$ & $\begin{array}{l}\text { Liposomal } \\
\text { vaccination }\end{array}$ & $\begin{array}{l}\text { Number of } \\
\text { mice }\end{array}$ \\
\hline \multirow{2}{*}{$\begin{array}{l}\text { PBS }+ \\
\text { Addavax }\end{array}$} & PBS & 8 \\
\cline { 2 - 3 } & $\mathrm{E}(\mathrm{O})$ & 8 \\
\hline \multirow{2}{*}{$\begin{array}{l}\text { OVA }+ \\
\text { Addavax }\end{array}$} & $\mathrm{E}$ & 8 \\
\cline { 2 - 3 } & $\mathrm{E}()$ & 8 \\
\cline { 2 - 3 } & $\mathrm{E}(\mathrm{O})$ & 8 \\
\hline
\end{tabular}

Table S3: Number of mice in each group for vaccination study with a larger cohort. Addavax is an immunoadjuvant similar to MF59; OVA is a peptide of Ovalbumin; E denotes free ErbB-2 peptide; $\mathrm{E}()$ liposomes surface decorated with ErbB-2 peptide but not containing OVA; $\mathrm{E}(\mathrm{O})$ OVA peptide encapsulating, ErbB-2 peptide surface decorated liposomes. 


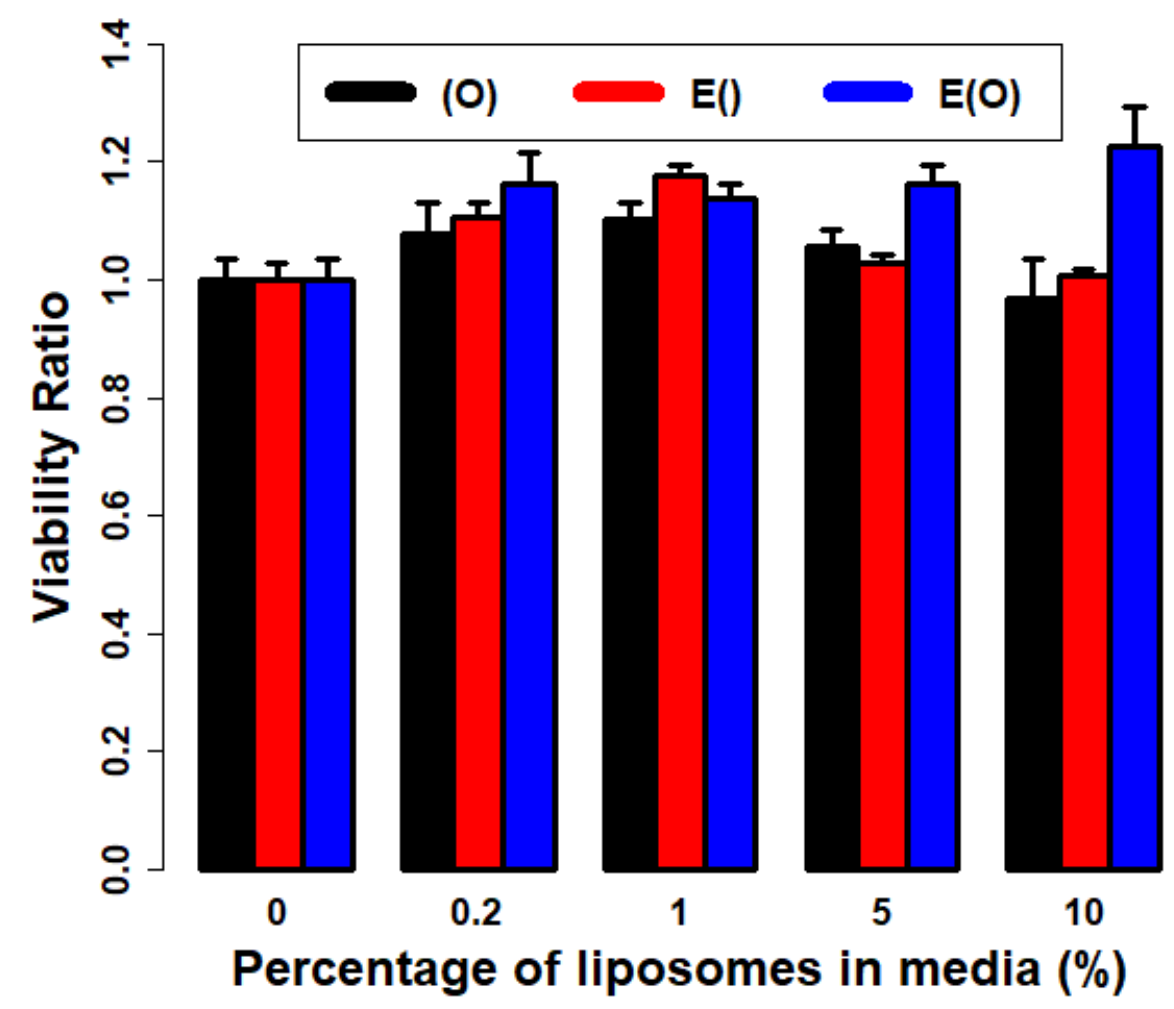

Figure S3: Cytotoxicity of liposomes: in vitro cytotoxicity of the liposomes was tested by an MTS assay on A549 cells, as described in methods section. Data is presented as a ratio of viability of sample wells compared to the average viability of untreated cells. Each bar represents the mean of $\mathrm{n}=5$ wells, error bars represent standard deviation. 


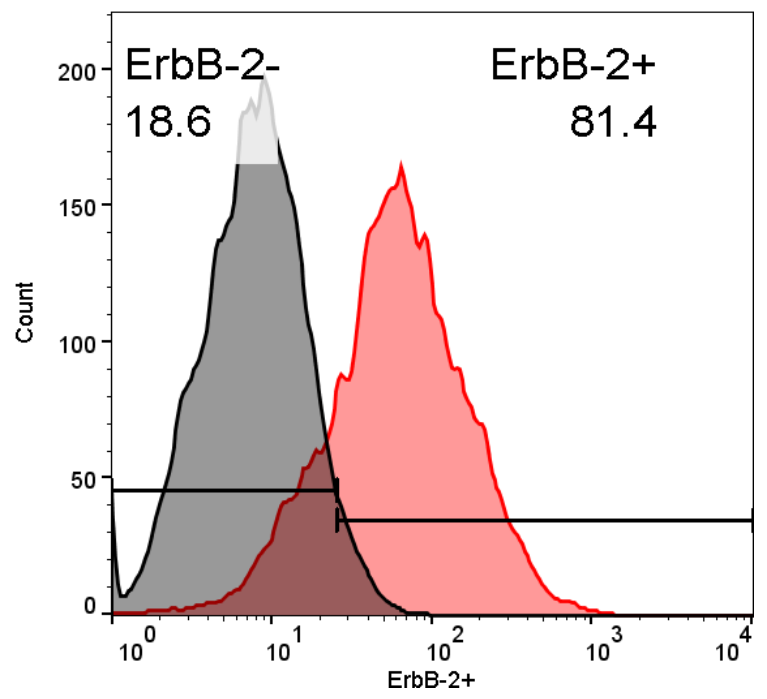

Figure S4: Flow cytometry of TUBO murine mammary cancer cells expression of rat ErbB-2 receptor. Grey histogram is unstained cells, while red is cells incubated with anti-rat ErbB-2 conjugated to AF488 on ice in the dark for 30 minutes. Each histogram represents the results of 10,000 events. Gating was chosen so that $5 \%$ of unstained cells were ErbB-2 false-positive. Profile representative of $n=3$. 


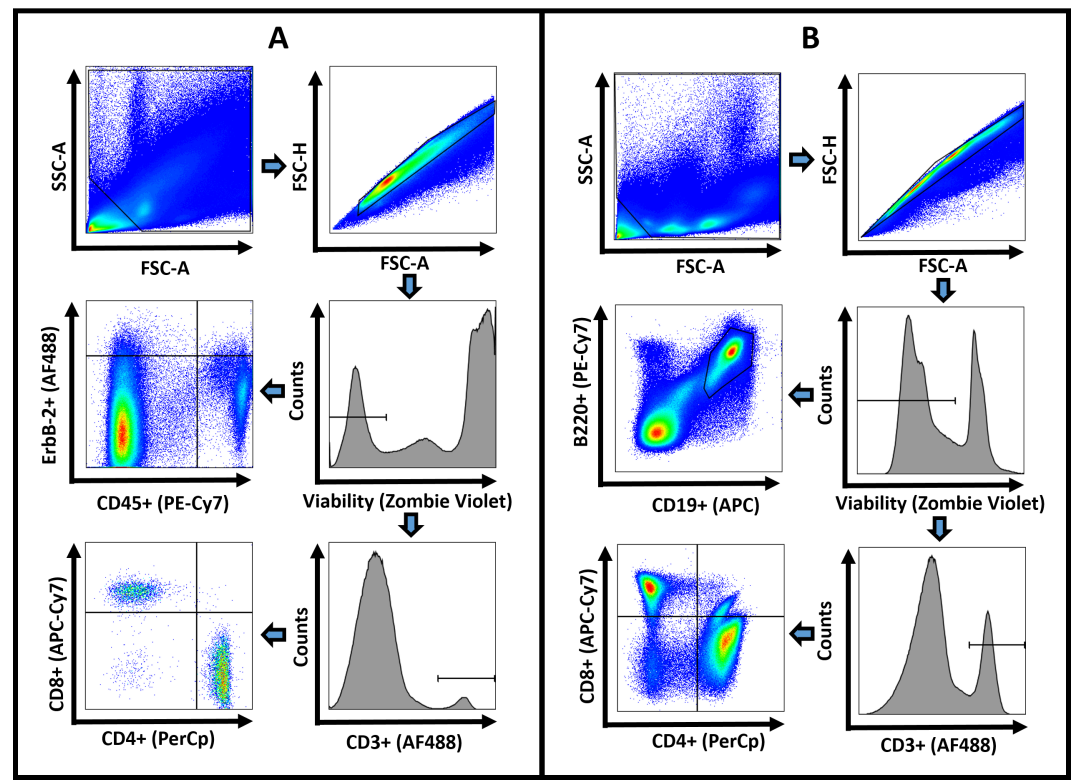

Figure S5: Gating strategy for flow cytometry of isolated single-cell suspensions from resected tumours (A) and spleens (B) of mice. Tumours and spleens were resected from 4 mice in each group with the largest tumours and processed into single-cell suspension as described in the methods section. Gating strategies were chosen based on comparing unstained, single-stained and full-minus-one (FMO) stained samples. Images shown here are the result of 20 samples pooled together for each respective tissue type. 


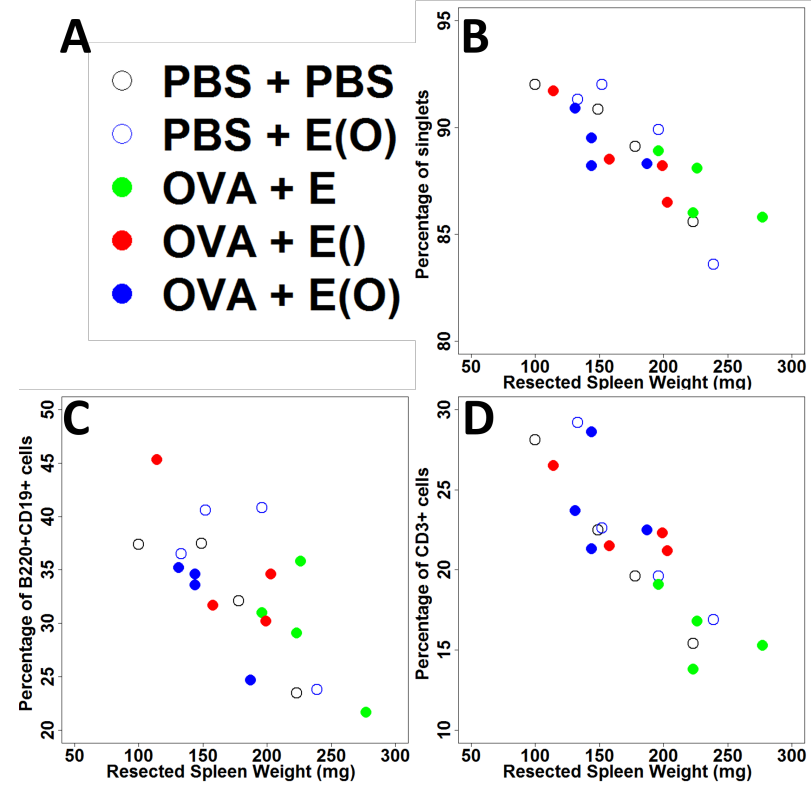

Figure S6: Linear trends between resected spleen weight and isolated cellular populations. Panel A shows a legend for the plots, panels B-D compare the spleen weight to the percentage of isolated singlets (panel B), B220+CD19+ (panel C), and CD3+ (panel D). 